\title{
Dynamic Analysis of Sandwich Auxetic Honeycomb Plates Subjected to Moving Oscillator Load on Elastic Foundation
}

\author{
Thanh Trung Tran, ${ }^{1}$ Quoc Hoa Pham $\mathbb{D D}^{2,3}{ }^{2,3}$ Trung Nguyen-Thoi, ${ }^{2,3}$ and The-Van Tran ${ }^{4}$ \\ ${ }^{1}$ Department of Mechanics, Le Quy Don Technical University, Hanoi, Vietnam \\ ${ }^{2}$ Division of Computational Mathematics and Engineering, Institute for Computational Science, Ton Duc Thang University, \\ Ho Chi Minh, Vietnam \\ ${ }^{3}$ Faculty of Civil Engineering, Ton Duc Thang University, Ho Chi Minh, Vietnam \\ ${ }^{4}$ Department of Mechanics, Tran Dai Nghia University, Ho Chi Minh, Vietnam
}

Correspondence should be addressed to Quoc Hoa Pham; phamquochoa@tdtu.edu.vn

Received 17 March 2020; Accepted 23 April 2020; Published 12 May 2020

Academic Editor: Hiroshi Yoshihara

Copyright (c) 2020 Thanh Trung Tran et al. This is an open access article distributed under the Creative Commons Attribution License, which permits unrestricted use, distribution, and reproduction in any medium, provided the original work is properly cited.

\begin{abstract}
Based on Mindlin plate theory and finite element method (FEM), dynamic response analysis of sandwich composite plates with auxetic honeycomb core resting on the elastic foundation (EF) under moving oscillator load is investigated in this work. Moving oscillator load includes spring-elastic $k$ and damper $c$. The EF with two coefficients was modelled by Winkler and Pasternak. The system of equations of motion of the sandwich composite plate can be solved by Newmark's direct integration method. The reliability of the present method is verified through comparison with the results other methods available in the literature. In addition, the effects of structural parameters, material properties, and moving oscillator loads to the dynamic response of the auxetic honeycomb plate are studied.
\end{abstract}

\section{Introduction}

The composite auxetic material with negative Poisson's ratio is an advanced material with many outstanding benefits due to the excellent performance of ultra-light, higher stiffness, strength-to-weight ratio, and well energy absorption capacity from loads, especially the types of loads that make the structures vibrate as large as blast loads, moving loads, and impact loads, etc. Therefore, it has been used in many areas including civil and defence. With the advantageous features in many practical applications, this material has been extensively interested in the word by scientists with many different methods, including the field of mechanical calculation.

Considering material with negative Poisson's ratio, Almgren [1] presented an isotropic three-dimensional structure with equal Poisson's ratio. Whitty et al. [2] designed sandwich composite plates with increased mechanical and thermal properties by the effect of Poisson ratios in in-plane. In [3], Ruzzene and coworkers investigated the wave propagation in sandwich structures with the cyclical auxetic core layer. Jensen and his colleagues [4] survey the effects of Poisson's ratio on the membrane deformation of the structures under indentation. Qian-Tian and Zhi-Chun [5] studied the wave propagation in sandwich composite plates with the auxetic core. Hadjigeorgiou and Stavroulakis [6] proposed the use of auxetic materials in advanced structures. In [7-9], Teik-Cheng considered the shear deformation, auxetic foundation in plates, and thermal stresses in both plates and shell structures. Prawoto [10] studied and reviewed the structure with negative Poisson's ratio. Strek and coworkers [11] analyzed the response of dynamic sandwich plates with auxetic cores. Scarpa and Tomlinson [12] considered the theoretical characteristics of the vibration of sandwich composite plates with in-plane negative Poisson's ratio values. Yang and his colleagues [13] used the FEM to study the geometric effects on the micropolar elastic honeycomb structure. Imbalzano et al. 
[14] studied the three-dimensional modelling of auxetic sandwich composite plates for localized impact resistance and considered sandwich composite plates with auxetic core layer under blast loadings in Ref [15]. Huang and coworkers [16] investigated the in-plane mechanics of a novel zero Poisson's ratio honeycomb core. Jin et al. [17] examined the effects of size on the mechanical behavior of hexagonal honeycombs in in-plane. Arbaoui and coworkers [18] analyzed the static bending of multilayer sandwich structures by numerical simulation and experimental methods. Yongcun and his colleagues [19] presented the buckling of a rectangular plate with auxetic material under uniaxial compression. Xu and Deng [20] considered the wave propagation characteristics in thick conventional and auxetic cellular plates. Recently, Duc and his colleagues have a relatively complete research on the mechanical behavior of the sandwich composite structures with negative Poisson's ratio in the auxetic honeycomb core layer such as investigating dynamic nonlinear response and vibration of sandwich composite plates with auxetic honeycomb core layer by the analytical method [21]; static bending analysis of plate using FEM [22]; nonlinear forced and free vibration response of sandwich composite cylindrical panels [23]; the geometrically nonlinear dynamic response of eccentrically stiffened circular cylindrical shells [24]; double curved shallow shells using TSDT [25]; and evaluation of mechanical properties of composites reinforced by randomly distributed spherical particles with negative Poisson's ratios [26].

In the case of structures on EF, Zenkour and Radwan [27] have recently proposed an exact analytical approach to free vibration analysis of laminated composite and sandwich plates resting on EF using a plate theory with four unknown variables. Duc et al. [28] presented nonlinear thermal dynamic response of shear deformable functionally graded (FG) plates resting on EF. In [29], he and coworkers analyzed the dynamic response of composite double curved shallow shells with auxetic honeycomb core layer resting on EF under blast and damping loads. In his book [30], the results of the nonlinear dynamic analysis of FGM structures on EF are presented. Mahmoudi et al. [31] developed a refined quasi-three-dimensional shear deformation theory to analyze for FG sandwich plates resting on the two-parameter EF under thermomechanical loading.

Moving load is one of the most common types of load that affects the structures in practice. Besides, the influence of this load on the dynamic response of the system is very significant. Thus, the structures under the action of the moving load are studied by many scientists around the world. Other typical works such as Song et al. [32] presented the oscillation of FG plates with a moving volume, using Kirchhoff's plate theory and analytical method based on Rayleigh-Ritz's solution and penalty function. Malekzadeh and coworkers [33] analyzed the dynamic of laminated composite plates subjected to moving load based on the analytical method. Ouyang [34] briefly reviewed a variety of moving-load problems and several analytical solution methods. Nguyen and coworkers [35] programed triplelayer composite plates with layers connected by shear connectors subjected to moving load by FEM. Song et al. [36] investigated the dynamic of rectangular thin plates of arbitrary boundary conditions under moving loads using the analytical method. Fryba [37] has summarized a variety of engineering problems that analyzed the dynamics of structures under moving loads. The above literature reviews indicate mainly the analysis of free vibration and forced vibration when moving load or moving mass is on a straight line parallel to an edge of the plate. The research results on plate structure are influenced by the moving load with oscillation system which takes into account the interaction between structure and load as well as the investigation of any motion orbit of the load is not much.

According to the best of authors' knowledge, the researchers only focus on investigating static bending, free vibration, and the dynamics of the sandwich structures with Poisson's ratio in auxetic honeycomb layer. Nevertheless, the dynamic response of the sandwich composite plate with honeycomb core layer subject to moving oscillator load has not been published yet. In this article, the dynamic response of plates with the auxetic honeycomb core layer subjected to moving oscillator load resting on $\mathrm{EF}$ is investigated numerically. The results of the present work may be applied for computation in many civil engineering problems such as vehicles running on roads, the rails resting on the EF subject to moving oscillator loads, and aeroplanes moving on runways. The sandwich composite plates used in the present study have three layers in which the top and bottom layers are isotropic materials; the core layer is auxetic honeycomb using the same material. In the present formulation, the firstorder shear deformation theory (FSDT) combining with FEM is used to build the equation of motion for the sandwich auxetic honeycomb plate and to validate the results of the proposed equations with published works to verify accuracy and reliability. Finally, the influence of geometric parameters, material, load, etc., on the dynamic response of the referred plate under the moving oscillator load is investigated.

\section{Computational Model and Assumptions}

Consider plates have the length $a$, width $b$, and thickness $h$. The plate is made from materials with negative Poisson's ratio in auxetic honeycomb subjected to the moving oscillator load consisting of two masses $m_{1}$ and $m_{2}$, and they are connected with spring-elastic $k$ and viscous bonds $c$ as shown in Figure 1.

The moving load moves with any orbit depending on $(x$ $(t), y(t))$ which is the position of mass $m_{1}$.

The dynamic response of the plate consists of displacement, velocity, acceleration, and stress at any point in the plate. The sandwich composite plate resting on EF is shown in Figure 1. The reaction-deflection relation of Winkler-Pasternak foundation is given by [21, 27]

$$
\mathbf{q}_{e}=K_{1} w-K_{2} \nabla^{2} w,
$$

where $\nabla^{2}=\partial^{2} / \partial x^{2}+\partial^{2} / \partial y^{2}$ and $w$ is the displacement of the sandwich composite plate with honeycomb core layer; $K_{1}$ 


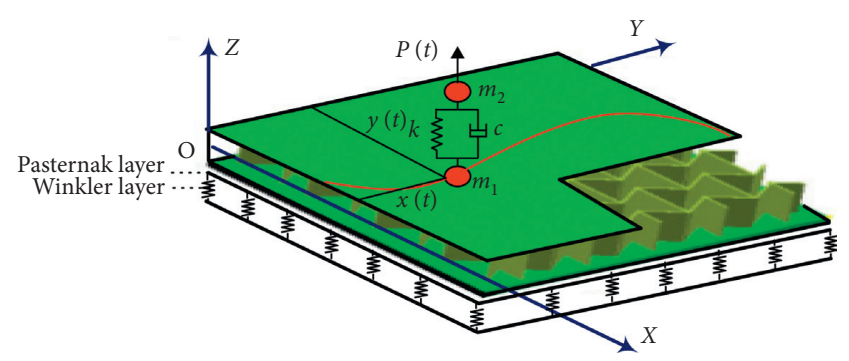

FIgURE 1: Model of the sandwich composite plate with negative Poisson's ratio in auxetic honeycomb core layer subjected to moving oscillator load on EF.

and $K_{2}$ are, respectively, Winkler foundation stiffness and shear layer stiffness of the Pasternak foundation.

\section{Material Properties of the Auxetic Honeycomb Core Layer}

This paper researches the sandwich composite plate with the auxetic honeycomb core layer with negative Poisson's ratio. Unit cells of auxetic honeycomb core layer have geometric parameters as $[5,21]$ shown in Figure 2, in which $l$ is the length of the inclined cell rib, $h$ is the length of the vertical cell rib, $\theta$ is the inclined angle, and $\alpha$ and $\beta$ define the relative cell wall length and the wall's slenderness ratio, respectively, which are important parameters in honeycomb property. The material property of the honeycomb core layer structures is given by $[5,21]$

$$
\begin{aligned}
E_{1}^{C} & =E\left(\frac{t}{l}\right)^{3} \frac{\cos \theta}{((h / l)+\sin \theta) \sin ^{2} \theta}, \\
E_{2}^{C} & =E\left(\frac{t}{l}\right)^{3} \frac{((h / l)+\sin \theta)}{\cos ^{3} \theta}, \\
\nu_{12}^{C} & =\frac{\cos ^{2} \theta}{((h / l)+\sin \theta) \sin \theta}, \\
G_{12}^{C} & =E\left(\frac{t}{l}\right)^{3} \frac{((h / l)+\sin \theta)}{(h / l)^{2}(2(h / l)+1) \cos \theta}, \\
G_{13}^{C} & =G\left(\frac{t}{l}\right) \frac{\cos \theta}{((h / l)+\sin \theta)}, \\
G_{23}^{C} & =G\left(\frac{t}{l}\right) \frac{1+2 \sin { }^{2} \theta}{2 \cos \theta((h / l)+\sin \theta)}, \\
\rho^{C} & =\rho \frac{(t / l)((h / l)+2)}{2 \cos \theta((h / l)+\sin \theta)},
\end{aligned}
$$

in which " $c$ " represents core material, and $E, G$, and $\rho$ are Young's moduli, shear moduli, and mass density of the material.

From Figure 3, it can be observed that when the angle turns to be negative values gradually, Poisson's ratio also comes with negative values. In the range from $-80^{\circ}$ to $80^{\circ}$, when $\theta=0$, value $\nu_{12}$ is equal to zero. However, in the case of

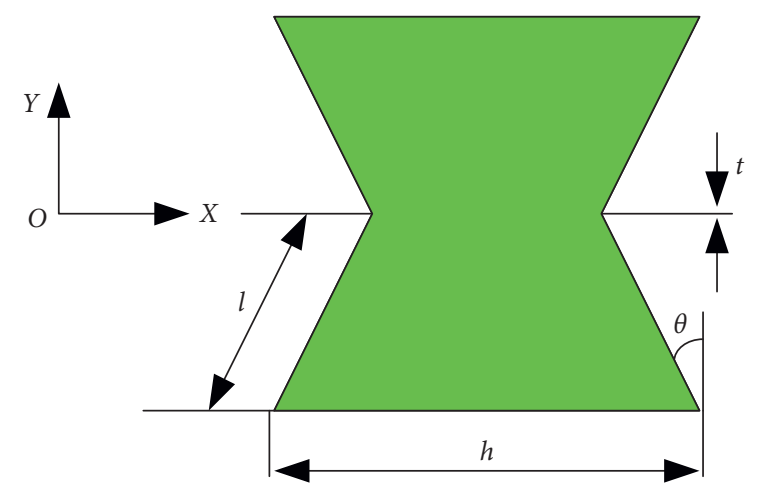

FIGURE 2: Model of the cell of the auxetic honeycomb core layer.

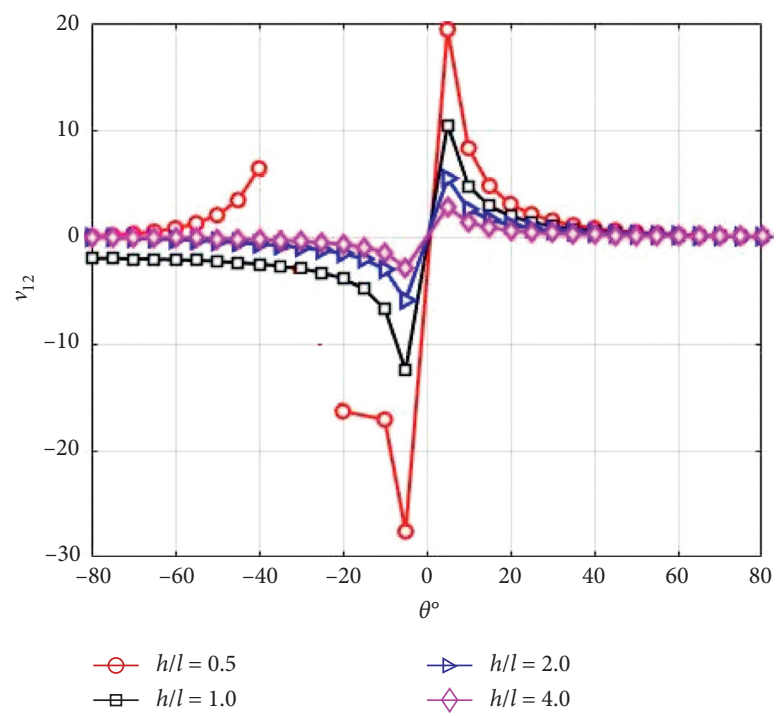

Figure 3: Effect of cell angle on Poisson's ratio with different $h / l$ ratios.

$\theta=-30^{\circ}$ and $h / l=0.5$, value $\nu_{12}$ is undefined, and therefore, this line is discontinuous.

\section{Finite Element Model for Dynamic Analysis of Sandwich Composite Plates with Negative Poisson's Ratio in the Auxetic Honeycomb Core Layer}

4.1. The Equation of Motion for Plate Element. The displacement field of Reddy's FSDT is of the following form [38]:

$$
\left\{\begin{array}{l}
u(x, y, z)=u_{0}(x, y, 0)+z \cdot \psi_{x} \\
v(x, y, z)=v_{0}(x, y, 0)+z \cdot \psi_{y} \\
w(x, y, z)=w_{0}(x, y, 0)
\end{array}\right.
$$

where $u_{0}, v_{0}, w_{0}$ are the displacements at midplane $(z=0)$ and $\psi_{x}, \psi_{y}$ are the transverse normal rotations of the $y$ - and $x$-axes.

The deformed components due to bending at the point of coordinates $(x, y, z)$ are given by 


$$
\varepsilon_{b}=\varepsilon_{0}+z \gamma
$$

where

$$
\begin{aligned}
& \boldsymbol{\varepsilon}_{0}=\left\{\frac{\partial u_{0}}{\partial x}, \frac{\partial v_{0}}{\partial y}, \frac{\partial u_{0}}{\partial y}+\frac{\partial v_{0}}{\partial x}\right\}^{T}, \\
& \boldsymbol{\gamma}=\left\{\frac{\partial \psi_{x}}{\partial x}, \frac{\partial \psi_{y}}{\partial y}, \frac{\partial \psi_{x}}{\partial y}+\frac{\partial \psi_{y}}{\partial x}\right\}^{T} .
\end{aligned}
$$

The deformed components due to shear at points with coordinates $(x, y, z)$ are given by

$$
\boldsymbol{\varepsilon}_{s}=\left\{\begin{array}{c}
\gamma_{y z} \\
\gamma_{x z}
\end{array}\right\}=\left\{\begin{array}{c}
\psi_{y}+\frac{\partial w_{0}}{\partial y} \\
\psi_{x}+\frac{\partial w_{0}}{\partial x}
\end{array}\right\} .
$$

Stress due to bending deformation at the point of coordinates $(x, y, z)$ is as follows:

$$
\boldsymbol{\sigma}_{b}=\left[\begin{array}{lll}
\sigma_{x} & \sigma_{y} & \tau_{x y}
\end{array}\right]^{T}=\mathbf{D}_{b} \boldsymbol{\varepsilon}_{b}
$$

in which

$$
\mathbf{D}_{b}=\left[\begin{array}{ccc}
Q_{11} & Q_{12} & 0 \\
Q_{12} & Q_{22} & 0 \\
0 & 0 & Q_{44}
\end{array}\right]
$$

The components in equation (9) are determined by the following equation:

$$
\begin{aligned}
& Q_{11}=\frac{E_{1}}{1-v_{12} v_{21}}, \\
& Q_{22}=\frac{E_{2}}{1-v_{12} v_{21}}, \\
& Q_{12}=\frac{v_{12} E_{2}}{1-v_{12} \nu_{21}}, \\
& Q_{44}=\frac{E_{1}}{2\left(1+v_{12}\right)} .
\end{aligned}
$$

Stress due to shear strain at a point $(x, y, z)$ is given by

$$
\begin{aligned}
& \boldsymbol{\sigma}_{s}=\left[\begin{array}{ll}
\tau_{y z} & \tau_{x z}
\end{array}\right]^{T}=\mathbf{D}_{s} \boldsymbol{\varepsilon}_{s}, \\
& \mathbf{D}_{s}=\left[\begin{array}{cc}
Q_{55} & 0 \\
0 & Q_{66}
\end{array}\right] .
\end{aligned}
$$

The components in equation (12) are determined as follows:

$$
Q_{55}=Q_{66}=\frac{E_{1}}{2\left(1+v_{12}\right)} \text {. }
$$

In the present study, an eight-node isoparametric element with five degrees of freedom (DOFs) for each node is employed. The DOFs of the $i^{\text {th }}$ node $\mathbf{q}_{e}^{i}$ and plate element $\mathbf{q}_{e}$ are defined as follows:

$$
\begin{aligned}
& \mathbf{q}_{e}^{i}=\left\{\begin{array}{lllll}
u_{0 i} & v_{0 i} & w_{0 i} & \psi_{x i} & \psi_{y i}
\end{array}\right\}^{T}, \quad i=1, \ldots, 8, \\
& \mathbf{q}_{e}=\left\{\begin{array}{llllllll}
\mathbf{q}_{e}^{1} & \mathbf{q}_{e}^{2} & \mathbf{q}_{e}^{3} & \mathbf{q}_{e}^{4} & \mathbf{q}_{e}^{5} & \mathbf{q}_{e}^{6} & \mathbf{q}_{e}^{7} & \mathbf{q}_{e}^{8}
\end{array}\right\}^{T}, \\
& u_{0}=\sum_{i=1}^{8} N_{i}(\xi, \eta) u_{0 i} \\
& v_{0}=\sum_{i=1}^{8} N_{i}(\xi, \eta) v_{0 i} \text {, } \\
& w=\sum_{i=1}^{8} N_{i}(\zeta, \eta) w_{0 i} \\
& \psi_{x}=\sum_{i=1}^{8} N_{i}(\xi, \eta) \psi_{x i} \text {, } \\
& \psi_{y}=\sum_{i=1}^{8} N_{i}(\xi, \eta) \psi_{y i}
\end{aligned}
$$

where $N_{i}(i=1, \ldots, 8)$ is the shape function and specified in Appendix A.

The equation of motion for a plate element can be derived from the virtual work principle as follows:

$$
\begin{aligned}
& \int_{V_{e}} \delta \dot{\mathbf{q}}_{e}^{T} \rho \dot{\mathbf{q}}_{e} \mathrm{~d} V_{e}+\int_{V_{e}} \delta \boldsymbol{\varepsilon}^{T} \mathbf{D}_{b} \boldsymbol{\varepsilon} \mathrm{d} V_{e}+\int_{V_{e}} \delta \boldsymbol{\gamma}^{T} \mathbf{D}_{s} \gamma \mathrm{d} V_{e} \\
& \quad+\int_{A_{e}} \delta w^{T}\left[K_{1} w-K_{2}\left(\frac{\partial^{2} w}{\partial x^{2}}+\frac{\partial^{2} w}{\partial y^{2}}\right)\right] \mathrm{d} A_{e}-\delta \mathbf{q}_{e}^{T} \int_{A_{e}} \mathbf{N}_{w} p(t) \mathrm{d} A_{e}=0,
\end{aligned}
$$

in which $A_{e}$ and $V_{e}$ are the area and volume of the element, respectively.

By substituting equations (5)-(8) and (15) into equation (17), the equation of motion according to the finite element formulation for the plate element is obtained:

$$
\mathbf{M}_{e}^{p} \ddot{\mathbf{q}}_{e}+\left(\mathbf{K}_{e}^{p}+\mathbf{K}_{e}^{f w}+\mathbf{K}_{e}^{f p}\right) \mathbf{q}_{e}=\mathbf{F}_{e}
$$

where the stiffness matrix $\mathbf{K}_{e}^{p}$ is given by

$$
\begin{aligned}
\mathbf{K}_{e}^{p}= & \int_{A_{e}}\left[\mathbf{B}_{1}^{T} \mathbf{A B}_{1}+\mathbf{B}_{1}^{T} \mathbf{B B}_{2}+\mathbf{B}_{2}^{T} \mathbf{B B}_{1}+\mathbf{B}_{2}^{T} \mathbf{D} \mathbf{B}_{2}\right] \mathrm{d} x \mathrm{~d} y \\
& +\xi \int_{A_{e}}\left[\mathbf{B}_{3}^{T} \mathbf{A}_{p} \mathbf{B}_{3}\right] \mathrm{d} x \mathrm{~d} y,
\end{aligned}
$$

where $\xi=5 / 6$ is the shear correction factor. The gradient strain matrices in equation (19) are determined by the following formulas:

$$
\begin{aligned}
& \mathbf{B}_{1}=\left[\begin{array}{llllllll}
\mathbf{B}_{1}^{1} & \mathbf{B}_{1}^{2} & \mathbf{B}_{1}^{3} & \mathbf{B}_{1}^{4} & \mathbf{B}_{1}^{5} & \mathbf{B}_{1}^{6} & \mathbf{B}_{1}^{7} & \mathbf{B}_{1}^{8}
\end{array}\right], \\
& \mathbf{B}_{2}=\left[\begin{array}{llllllll}
\mathbf{B}_{2}^{1} & \mathbf{B}_{2}^{2} & \mathbf{B}_{2}^{3} & \mathbf{B}_{2}^{4} & \mathbf{B}_{2}^{5} & \mathbf{B}_{2}^{6} & \mathbf{B}_{2}^{7} & \mathbf{B}_{2}^{8}
\end{array}\right], \\
& \mathbf{B}_{3}=\left[\begin{array}{llllllll}
\mathbf{B}_{3}^{1} & \mathbf{B}_{3}^{2} & \mathbf{B}_{3}^{3} & \mathbf{B}_{3}^{4} & \mathbf{B}_{3}^{5} & \mathbf{B}_{3}^{6} & \mathbf{B}_{3}^{7} & \mathbf{B}_{3}^{8}
\end{array}\right] .
\end{aligned}
$$

Note that $\mathbf{B}_{1}^{\mathrm{i}}, \mathbf{B}_{2}^{\mathrm{i}}$, and $\mathbf{B}_{3}^{\mathrm{i}}$ are shown in Appendix $\mathrm{B}$.

Material stiffness matrices are determined by the following formulas: 


$$
\begin{aligned}
(\mathbf{A} ; \mathbf{B} ; \mathbf{D}) & =\int_{-h / 2}^{h / 2}\left(1 ; z ; z^{2}\right)\left[\begin{array}{ccc}
Q_{11} & Q_{12} & 0 \\
Q_{12} & Q_{22} & 0 \\
0 & 0 & Q_{44}
\end{array}\right] \mathrm{d} z, \\
\mathbf{A}_{p} & =\int_{-h / 2}^{h / 2}\left[\begin{array}{cc}
Q_{55} & 0 \\
0 & Q_{66}
\end{array}\right] \mathrm{d} z .
\end{aligned}
$$

Stiffness matrices of elastic foundation:

(i) For Galerkin foundation:

$$
\mathbf{K}_{e}^{f w}=K_{1} \int_{A_{e}} \mathbf{N}_{w}^{T} \mathbf{N}_{w} \mathrm{~d} x \mathrm{~d} y .
$$

(i) For Pasternak foundation:

$$
\mathbf{K}_{e}^{f p}=K_{2} \int_{A_{e}}\left[\left(\frac{\partial \mathbf{N}_{w}}{\partial x}\right)^{T}\left(\frac{\partial \mathbf{N}_{w}}{\partial x}\right)+\left(\frac{\partial \mathbf{N}_{w}}{\partial y}\right)^{T}\left(\frac{\partial \mathbf{N}_{w}}{\partial y}\right)\right] \mathrm{d} x \mathrm{~d} y
$$

where $\mathbf{N}_{w}$ is shown in Appendix C.

Mass matrix of the plate element:

$$
\mathbf{M}_{e}^{p}=\int_{A_{e}} \mathbf{N}^{T}\left(\rho \int_{-h / 2}^{h / 2} \mathbf{L}^{T} \mathbf{L} \mathrm{d} z\right) \mathbf{N} \mathrm{d} x \mathrm{~d} y,
$$

in which

$$
N=\left[\begin{array}{llllll}
N_{1} \mathbf{I}_{5 \times 5} & N_{2} \mathbf{I}_{5 \times 5} & \ldots & N_{7} I_{5 \times 5} & N_{8} I_{5 \times 5}
\end{array}\right],
$$

with $\mathbf{I}_{5 \times 5}$ is the unit matrix rank $5 \times 5$, and

$$
\mathbf{L}=\left[\begin{array}{lllll}
1 & 0 & 0 & z & 0 \\
0 & 1 & 0 & 0 & z \\
0 & 0 & 1 & 0 & 0
\end{array}\right]
$$

The load vector in the case of distributed uniform load $p$ $(x, y)$ on the surface of the element is given by

$$
\mathbf{F}_{e}=\int_{A_{e}} \mathbf{N}^{\mathrm{T}} \mathbf{p} \mathrm{d} x \mathrm{~d} y
$$

in which

$$
\mathbf{p}=\left\{\begin{array}{llllll}
0 & 0 & p(x, y, t) & 0 & 0
\end{array}\right\}^{T} .
$$

The stiffness matrices, mass matrices, and nodal load vectors of the element are calculated by using the Gaussian integral method.

4.2. Formulation of the Moving Oscillator Load. Consider the plate element subjected to the moving oscillator load as shown in Figure 4. At time $t$, the moving oscillator load is located on an element at the coordinate $(x(t), y(t))$.

The interaction force caused by the moving load on the plate element is written as follows:

$$
R(x, y, t)=P(t)-\left(m_{1}+m_{2}\right) g-m_{1} \ddot{w}-m_{2} \ddot{f},
$$

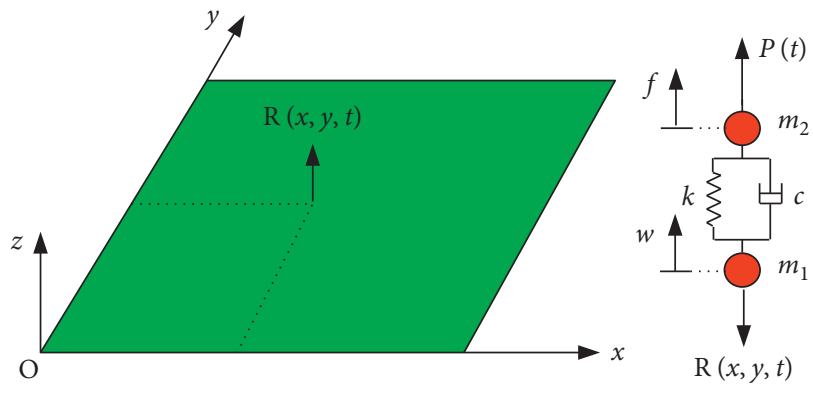

FIgURE 4: The plate element model under moving oscillator load.

where $f$ represents the displacement along the $z$-axis of mass $m_{2}$ and

$$
\begin{aligned}
\ddot{w}= & {\left[\ddot{x} \frac{\partial \mathbf{N}_{w}}{\partial x}+\ddot{y} \frac{\partial \mathbf{N}_{w}}{\partial y}+\dot{x}^{2} \frac{\partial^{2} \mathbf{N}_{w}}{\partial x^{2}}+\dot{y}^{2} \frac{\partial^{2} \mathbf{N}_{w}}{\partial y^{2}}+2 \dot{x} \dot{y} \frac{\partial^{2} \mathbf{N}_{w}}{\partial x \partial y}\right] \mathbf{q}_{e} } \\
& +\left[2 \dot{x} \frac{\partial \mathbf{N}_{w}}{\partial x}+2 \dot{y} \frac{\partial \mathbf{N}_{w}}{\partial y}\right] \dot{q}_{e}+\mathbf{N}_{w} \ddot{q}_{e} .
\end{aligned}
$$

Rewrite the equation in brief form:

$$
\ddot{w}=\mathbf{K}_{e}^{w} \mathbf{q}_{e}+\mathbf{C}_{e}^{w} \dot{\mathbf{q}}_{e}+\mathbf{N}_{w} \ddot{\mathbf{q}}_{e},
$$

in which the matrices are defined as follows:

$$
\mathbf{K}_{e}^{w}=\ddot{x} \frac{\partial \mathbf{N}_{w}}{\partial x}+\ddot{y} \frac{\partial \mathbf{N}_{w}}{\partial y}+\dot{x}^{2} \frac{\partial^{2} \mathbf{N}_{w}}{\partial x^{2}}+\dot{y}^{2} \frac{\partial^{2} \mathbf{N}_{w}}{\partial y^{2}}+2 \dot{x} \dot{y} \frac{\partial^{2} \mathbf{N}_{w}}{\partial x \partial y},
$$

$$
\mathbf{C}_{e}^{w}=2 \dot{x} \frac{\partial \mathbf{N}_{w}}{\partial x}+2 \dot{y} \frac{\partial \mathbf{N}_{w}}{\partial y}
$$

Using delta Dirac function, force is distributed by the following formula:

$$
p(x, y, t)=R(x, y, t) \delta\left(x-\eta_{m}\right) \delta\left(y-\xi_{m}\right) .
$$

4.3. The Equation of Motion of the Plate under Moving Oscillator Load. The differential equations of motion of the plate element on EF can be written as follows:

$$
\mathbf{M}_{e}^{p} \ddot{\mathbf{q}}_{e}+\mathbf{C}_{e}^{p} \dot{\mathbf{q}}_{e}+\left(\mathbf{K}_{e}^{p}+\mathbf{K}_{e}^{f w}+\mathbf{K}_{e}^{f p}\right) \mathbf{q}_{e}=\mathbf{F}_{e}(t) .
$$

In order to find the moving oscillator load $\mathbf{F}_{e}(t)$, substituting equation (31) into equation (29) and then into equation (34), the following equation is obtained:

$$
\begin{aligned}
\mathbf{F}_{e}(t)= & \left(P(t)-\left(m_{1}+m_{2}\right) g\right) \mathbf{N}_{w}^{T}-m_{1} \mathbf{N}_{w}^{T} \mathbf{K}_{e}^{w} \mathbf{q}_{e}-m_{1} \mathbf{N}_{w}^{T} \mathbf{C}_{e}^{w} \dot{q}_{e} \\
& -m_{1} \mathbf{N}_{w}^{T} \mathbf{N}_{e} \mathbf{q}_{e}-m_{2} \mathbf{N}_{w}^{T} \ddot{f},
\end{aligned}
$$

in which $\mathbf{N}_{w}$ receives the value at the coordinate $\left(x_{m}, y_{m}\right)$ which is the position of the moving load.

By substituting equation (36) into equation (35), we obtained the following equation: 


$$
\begin{aligned}
& \left(\mathbf{M}_{e}^{p}+\mathbf{M}_{e}^{m}\right) \ddot{\mathbf{q}}_{e}+\left(\mathbf{C}_{e}^{p}+\mathbf{C}_{e}^{m}\right) \dot{\mathbf{q}}_{e}+\left(\mathbf{K}_{e}^{p}+\mathbf{K}_{e}^{f w}+\mathbf{K}_{e}^{f p}+\mathbf{K}_{e}^{m}\right) \mathbf{q}_{e} \\
& \quad=\left(P(t)-\left(m_{1}+m_{2}\right) \mathrm{g}\right) \mathbf{N}_{w}^{T}-m_{2} \mathbf{N}_{w}^{T} \ddot{f},
\end{aligned}
$$

in which $\mathbf{C}_{e}^{p}=\alpha \mathbf{M}_{e}^{p}+\beta \mathbf{K}_{e}^{p}$ and $\alpha, \beta$ are Rayleigh drag coefficients defined in [37].

The differential equations of mass $m_{1}$ on moving oscillator load are as follows:

$$
m_{2} \ddot{f}+c \dot{f}+k f-c \dot{w}-k w=P(t),
$$

with

$$
\dot{w}=\left[\dot{x} \frac{\partial \mathbf{N}_{w}}{\partial x}+\dot{y} \frac{\partial \mathbf{N}_{w}}{\partial y}\right] \dot{q}_{e}+\mathbf{N}_{w} \mathbf{q}_{e}
$$
obtain

By substituting equation (39) into equation (38), we

$$
m_{2} \ddot{f}+c \dot{f}+k f-\left[c\left(\dot{x} \frac{\partial \mathbf{N}_{w}}{\partial x}+\dot{y} \frac{\partial \mathbf{N}_{w}}{\partial y}\right)+k \mathbf{N}_{w}\right] \mathbf{q}_{e}-c \mathbf{N}_{w} \dot{q}_{e}=P(t) .
$$

By combining equation (37) and equation (40), we have the system of differential equations of motion of the plate element and the mass $m_{2}$ of the moving load is as follows:

$$
\begin{aligned}
& {\left[\begin{array}{cc}
\mathbf{M}_{e}^{p}+\mathbf{M}_{e}^{m} & m_{1} \mathbf{N}_{w}^{T} \\
\mathbf{0} & m_{2}
\end{array}\right]\left\{\begin{array}{c}
\ddot{q}_{e} \\
\ddot{f}
\end{array}\right\}+\left[\begin{array}{cc}
\mathbf{C}_{e}^{p}+\mathbf{C}_{e}^{m} & \mathbf{0} \\
-c \mathbf{N}_{w} & c
\end{array}\right]\left\{\begin{array}{c}
\dot{q}_{e} \\
\dot{f}
\end{array}\right\}} \\
& +\left[\begin{array}{cc}
\mathbf{K}_{e}^{p}+\mathbf{K}_{e}^{f w}+\mathbf{K}_{e}^{f p}+\mathbf{K}_{e}^{m} & \mathbf{0} \\
c\left(\dot{x} \frac{\partial \mathbf{N}_{w}}{\partial x}+\dot{y} \frac{\partial \mathbf{N}_{w}}{\partial y}\right)+k \mathbf{N}_{w} & k
\end{array}\right]\left\{\begin{array}{l}
\mathbf{q}_{e} \\
f
\end{array}\right\} \\
& =\left\{\begin{array}{c}
\left(P(t)-\left(m_{1}+m_{2}\right) \mathrm{g}\right) \mathbf{N}_{w}^{T} \\
P(t)
\end{array}\right\},
\end{aligned}
$$

where

$$
\begin{aligned}
& \mathbf{M}_{e}^{m}=m_{1} \mathbf{N}_{w}^{T} \mathbf{N}_{w}, \\
& \mathbf{C}_{e}^{m}=m_{1} \mathbf{N}_{w}^{T} \mathbf{C}_{e}^{w}, \\
& \mathbf{K}_{e}^{m}=m_{2} \mathbf{N}_{w}^{T} \mathbf{K}_{e}^{w} .
\end{aligned}
$$

The system of differential equations of motion of the whole system is obtained after gathering matrices and element load vectors into the matrix and the vector global according to the general algorithm of FEM. Note that when there is a moving load with oscillation system on the plate, the DOFs of the system increase by one, and the extension of element matrices when there are moving loads in equation (41) is added. Rows and columns are extended in the global matrix according to the corresponding total DOFs. They are linear differential equations, which have the coefficient depending on time. To solve these equations, we use the Newmark-beta method [37]:
Step 1: discrete the mesh and determine the element matrix

Step 2: determine the global matrix when there is no moving load by assembling element matrices

Step 3: solve a separate oscillation problem and determine natural frequencies

Step 4: in each integral time step, determine the element matrix depending on the moving load, assembled into the global matrix (similar to Step 2)

Step 5: solve the system of equations in each time step and determine

Step 6: in each time step, determine stresses and internal forces

Step 7: export the dynamic response results of the system

Flowchart of the Newmark-beta method is shown in $[39,40]$.

\section{Numerical Results}

\subsection{Accuracy Study}

Example 1. Consider a rectangular plate with the simply supported-free-simply supported-free (SFSF-two short edges are simply supported and two long edges are free) boundary condition (BC). The plate has length $a=1 \mathrm{~m}$, width $b=a / 2$, thickness $h=a / 100$, Young's modulus $E=206.8 \mathrm{GPa}$, Poisson's ratio $\nu=0.29$, mass density $\rho=7820 \mathrm{~kg} / \mathrm{m}^{3}$ under moving load with mass $m=2.3 \mathrm{~kg}$ along $y=b / 2$ and $v=10 \mathrm{~m} / \mathrm{s}$ as in [36]. The authors use the established program with the different cases of meshes: $4 \times 4,6 \times 6,8 \times 8,10 \times 10,12 \times 12,14 \times 14$ to examine the displacement of the central point of the plate versus time. The numerical results with different meshes are compared with analytical solutions as shown in Table 1. From this, it is seen that using the mesh $12 \times 12$, the present results are in good agreement with the previous literature [36] in both the shape and magnitude as presented in Figure 5. This proved the reliability and the convergence of our finite element formulation.

Example 2. To be more reliable, we consider a fully simplesupport (SSSS) FGM plate with geometry parameters: the length $a=1 \mathrm{~m}$, the width $b=a$, and the thickness $h=a / 20$. The FGM plate is made of ceramic $\left(\mathrm{ZrO}_{2}\right)$ and metal (Al) with material characteristics as shown in Table 2 and volume factor ratio $k=1$. The nondimensional free vibration is computed as the following formula $\bar{\omega}=\omega h \sqrt{\rho_{m} / E_{m}}$. We use uniform mesh $12 \times 12$. The numerical results of the present method are compared with the analytical solutions [41] in Table 3.

From Table 3, it can be observed that the results of this work are in good agreement with the results of [41], and the error of the first four frequencies is less than $2 \%$.

5.2. Free Vibration of Sandwich Composite Plates with Negative Poisson's Ratio in Auxetic Honeycomb Core Layer. 
Table 1: Maximum deflections $w \times 10^{-5} \mathrm{~m}$ versus mesh density.

\begin{tabular}{lcccccc}
\hline $\begin{array}{l}\text { Case of } \\
\text { meshes }\end{array}$ & $4 \times 4$ & $6 \times 6$ & $8 \times 8$ & $10 \times 10$ & $12 \times 12$ & $14 \times 14$ \\
\hline $\begin{array}{l}\text { Present } \\
{[36]}\end{array}$ & 5.0413 & 5.3868 & 5.5803 & 5.6998 & 5.7020 & 5.7020 \\
\hline
\end{tabular}

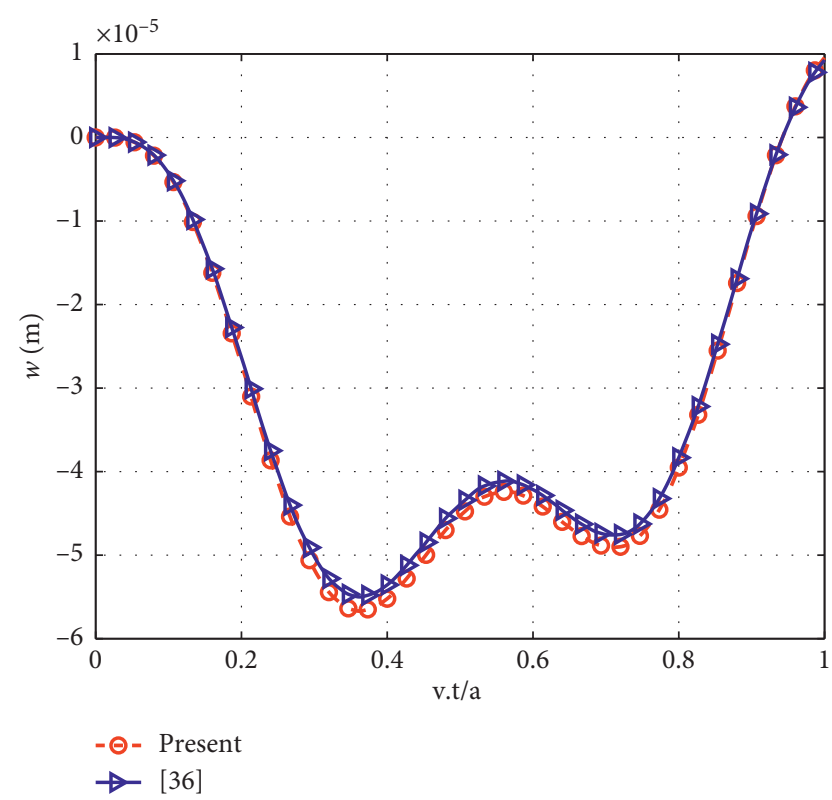

FIGURE 5: Deflections of the central point of the plate versus time.

TABle 2: Properties materials of FGM.

\begin{tabular}{lccc}
\hline Materials & $\begin{array}{c}\text { Young modulus } \\
(\mathrm{GPa})\end{array}$ & $\begin{array}{c}\text { Mass density }(\mathrm{kg} / \\
\left.\mathrm{m}^{3}\right)\end{array}$ & $\begin{array}{c}\text { Poisson's } \\
\text { ratio }\end{array}$ \\
\hline $\mathrm{ZrO}_{2}$ & $E_{c}=200$ & $\rho_{c}=5700$ & $\mu_{c}=0,3$ \\
$\mathrm{Al}$ & $E_{m}=70$ & $\rho_{m}=2707$ & $\mu_{m}=0,3$ \\
\hline
\end{tabular}

TABle 3: Nondimensional frequency $\bar{\omega}$.

\begin{tabular}{lcccc}
\hline $\bar{\omega}$ & Mode 1 & Mode 2 & Mode 3 & Mode 4 \\
\hline Present & 0.0161 & 0.1552 & 0.2603 & 2.2136 \\
{$[41]$} & 0.0158 & 0.1534 & 0.2592 & 2.2140 \\
Error $(\%)$ & 1.8 & 1,2 & 0.4 & 0.02 \\
\hline
\end{tabular}

Note that Error $(\%)=100 \times(\mid$ Present $-[41] \mid /[41])$.

In this section, an SSSS sandwich composite plate with three layers, the top layer, the bottom layer, and the auxetic honeycomb core layer, are considered. The top layer (thickness $h_{1}$ ) and bottom layer (thickness $h_{3}$ ) are isotropic aluminium material with geometrical parameters and materials properties: $h_{1}=h_{3}, E=69 \mathrm{GPa}, G=26 \mathrm{GPa}, v=0.33$, and $\rho=2700 \mathrm{~kg} / \mathrm{m}^{3}$. The core layer is the same material of other layers; geometrical parameters of the core layer are $h_{2}$, $\theta$, and ratio $h / l$ and $t / l$. The plate rests on EF with Winkler foundation stiffness $K_{1}(\mathrm{GPa} / \mathrm{m})$ and shear stiffness of Pasternak $K_{2}$ (GPa.m). Geometrical parameters of the sandwich composite plate are thickness $h=h_{1}+h_{2}+h_{3}$, length $a$, and width $b=a$.
The first natural frequencies with different values of the EF parameter and geometrical parameters of the core layer are presented in Table 4. It can be seen that the influence of geometrical parameters of the core layer on free vibration of the sandwich composite plates with the auxetic honeycomb core layer does not follow any rule. Note that when the EF parameters increase, natural frequencies of plate increase. Furthermore, numerical results show the EF parameters make the plate become stiffener and Pasternak's EF $\left(K_{2}\right)$ is more effective than Winkler's foundation $\left(K_{1}\right)$. For example, with $\theta=-35^{\circ}, h / l=0.5$ when $K_{1}=0.1 \mathrm{GPa} / \mathrm{m}$ and $K_{2}=0$, natural frequency $f_{1}=224.5746 \mathrm{~Hz}$, and if $K_{1}=0$ and $K_{2}=0.05 \mathrm{GPa} \cdot \mathrm{m}$, natural frequency $f_{1}=284.8829 \mathrm{~Hz}$. The first six mode shapes of the sandwich composite plate with honeycomb core layer are shown in Figure 6. In the case of the SSSS plate, the second and the third mode shapes are similar to each other. This phenomenon is suitable for the symmetrical plate structures under the same $\mathrm{BC}$ in the practice.

5.3. Numerical Results of the Dynamic Analysis of Sandwich Composite Plates with Negative Poisson's Ratio in Auxetic Honeycomb Core Layer. In this section, the authors consider an SFSF sandwich composite plate in which the core layer is auxetic honeycomb as Section 5.2. All layers have the same material $E=69 \mathrm{GPa}, G=26 \mathrm{GPa}, \nu=0.33$, and $\rho=2700 \mathrm{~kg} /$ $\mathrm{m}^{3}$, the geometrical parameters of the core layer are $h_{2}, \theta$, and ratio $h / l$ and $t / l$. Geometrical parameters of the sandwich composite plate are thickness $h=h_{1}+h_{2}+h_{3}$ in which $h_{1}$ and $h_{3}$ are the thickness of the top and bottom layers, respectively, length $a$, and width $b=a / 2$. The plate rests on EF with two parameters $K_{1}$ and $K_{2}$. The moving oscillator load (see Figure 1) with parameters $m_{1}, m_{2}, k$, and $c$ travels on the plate with any orbit with velocity $v$ and acceleration $a$.

5.3.1. Influence of the Ratio $h_{2} / h_{1}$. Firstly, let us consider a rectangular plate with $h=0.1 \mathrm{~m}, a=150 h, \theta=-55^{\circ}, h_{2} / 1=2$, $t / l=0.1385$, and $K_{1}=K_{2}=0$. The moving oscillator load with $m_{1}=m_{2}=100 \mathrm{~kg}, k=1.6 \mathrm{MN} / \mathrm{m}$, and $c=2500 \mathrm{Ns} / \mathrm{m}$ moves along $y=b / 2$ with velocity $v=15 \mathrm{~m} / \mathrm{s}$. The ratio $h_{2} / h_{1}=0,1$, $1.5,2$, and $2.5\left(h_{2} / h_{1}=0\right.$ is case of isotropic plate). The deflection, velocity, and stress of the plate central point are shown in Figure 7, and maximum deflections, velocities, and stress are illustrated in Table 5. Besides, the weight reduction of the sandwich composite plate with honeycomb core layer compared to the isotropic plate is also shown in this table.

From Figure 7 and Table 5, it can be observed that when the ratio $h_{\mathrm{c}} / h_{\mathrm{t}}$ is increased from 0 to 2.5 (i.e., increasing the thickness of the middle layer since the plate thickness $h$ is fixed), the deflection and the velocity of the central point of the plate are almost not changed. It is clear that the sandwich composite plates with honeycomb core layer help significantly absorb the vibration of structures and thus make the central deflection and velocity of plate reduce. In the case of the ratio $h_{2} / h_{1}$, it can be found that the mass of plate decreases significantly. Specifically, when $h_{2} / h_{1}=2.5$, the mass of the plate has decreased by $45 \%$ compared to the uniform plate. This is an impressive result. Therefore, to reduce the weight of the structure, we suggest 
TABLE 4: The first natural frequencies $(\mathrm{Hz})$ of the plate with different values of the EF parameters and geometry parameters of the core layer $\left(h=0.1 \mathrm{~m}, h_{2} / h_{1}=1.5, h_{1}=h_{3}, t / l=0.1385\right.$, and $\left.a=b=20 h\right)$.

\begin{tabular}{|c|c|c|c|c|c|}
\hline$\left(K_{1}, K_{2}\right)$ & $\theta^{\circ}$ & $h / l=0.5$ & $h / l=1$ & $h / l=2$ & $h / l=4$ \\
\hline \multirow{4}{*}{$(0,0)$} & $\theta=-10^{\circ}$ & 150.0868 & 151.6094 & 152.1649 & 152.4068 \\
\hline & $\theta=-35^{\circ}$ & 172.3232 & 149.7829 & 151.7055 & 152.1957 \\
\hline & $\theta=-55^{\circ}$ & 158.6420 & 142.8576 & 150.7676 & 151.7532 \\
\hline & $\theta=-80^{\circ}$ & 166.0869 & 58.71573 & 144.8534 & 148.7206 \\
\hline \multirow{4}{*}{$(0.1,0)$} & $\theta=-10^{\circ}$ & 195.4327 & 197.4288 & 198.1573 & 198.4744 \\
\hline & $\theta=-35^{\circ}$ & 224.5746 & 195.0387 & 197.5567 & 198.1988 \\
\hline & $\theta=-55^{\circ}$ & 206.6414 & 185.979 & 196.3308 & 197.6211 \\
\hline & $\theta=-80^{\circ}$ & 216.4098 & 76.28653 & 188.6021 & 193.6613 \\
\hline \multirow{4}{*}{$(0,0.05)$} & $\theta=-10^{\circ}$ & 247.8029 & 250.3433 & 251.2704 & 251.674 \\
\hline & $\theta=-35^{\circ}$ & 284.8829 & 247.3046 & 250.5073 & 251.3241 \\
\hline & $\theta=-55^{\circ}$ & 262.0626 & 235.7882 & 248.9498 & 250.5905 \\
\hline & $\theta=-80^{\circ}$ & 274.4996 & 96.61242 & 239.131 & 245.5620 \\
\hline \multirow{4}{*}{$(0.1,0.05)$} & $\theta=-10^{\circ}$ & 277.6223 & 280.4719 & 281.5118 & 281.9645 \\
\hline & $\theta=-35^{\circ}$ & 319.2125 & 277.0644 & 280.6563 & 281.5723 \\
\hline & $\theta=-55^{\circ}$ & 293.6156 & 264.1513 & 278.9102 & 280.7500 \\
\hline & $\theta=-80^{\circ}$ & 307.5683 & 108.1945 & 267.9027 & 275.1136 \\
\hline
\end{tabular}

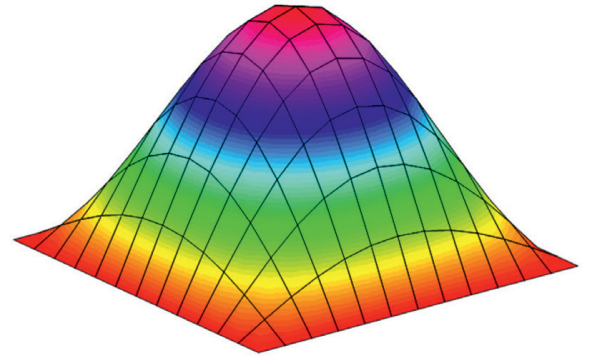

Mode 1

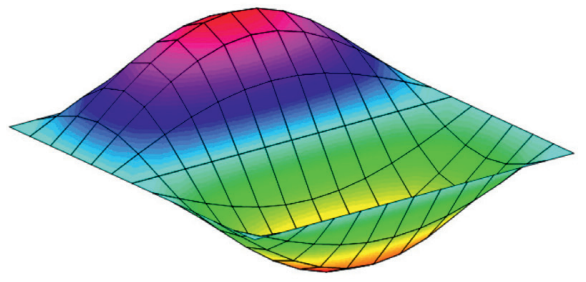

Mode 3

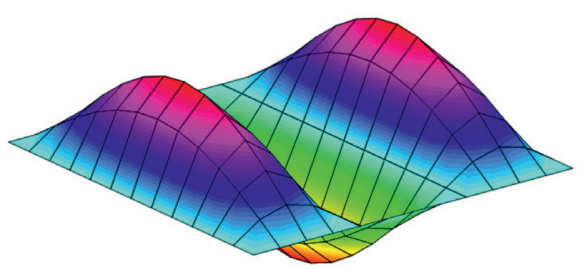

Mode 5

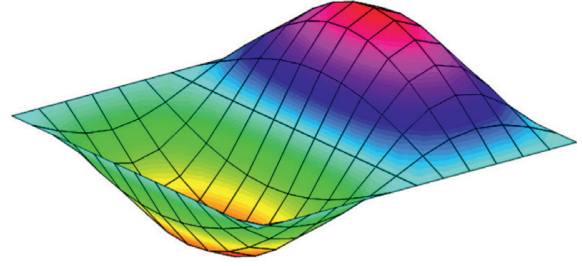

Mode 2

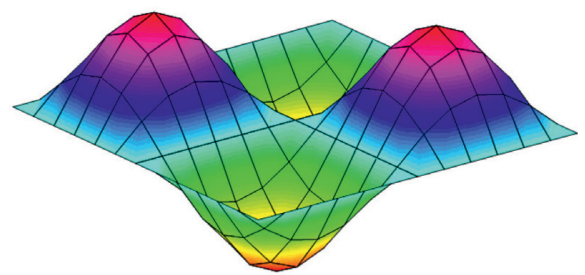

Mode 4

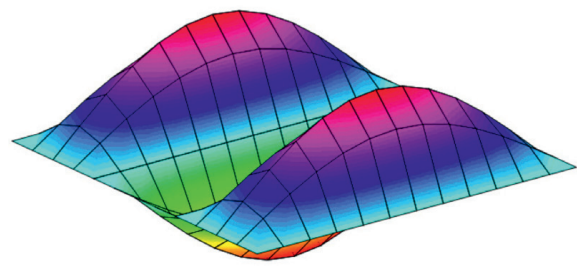

Mode 6

FIgURE 6: The first six mode shapes of the SSSS plate with $h=0.1 \mathrm{~m}, h_{2} / h_{1}=1.5, h_{1}=h_{3}, a=20 h, \theta=-55^{\circ}, h / l=2, t / l=0.1385$, and $K_{1}=K_{2}=0$.

using sandwich composite plates with honeycomb core layer instead of the anisotropic plates.

5.3.2. Influence of the Velocity $v$. Secondly, we consider an SFSF rectangular plate with $h=0.1 \mathrm{~m}, a=150 h, h / l=2$, $t / l=0.1385, K_{1}=K_{2}=0$, and $h_{2} / h_{1}=1.5$. The moving oscillator load with $m_{1}=m_{2}=100 \mathrm{~kg}, k=1.6 \mathrm{MN} / \mathrm{m}$, and $c=2500 \mathrm{Ns} / \mathrm{m}$ travels along $y=b / 2$ with velocity $v=5,10,15,20$, and $25 \mathrm{~m} / \mathrm{s}$ and acceleration $a=0$. The deflection, velocity, and stress of the plate central point are shown in Figure 8, and maximum deflections, velocities, and stress are illustrated in Table 6.

With material properties and geometrical parameters as in Section 5.3.1, the change in velocities is from 5 to $25 \mathrm{~m} / \mathrm{s}$. The response of the displacement, velocity, and stress of the 


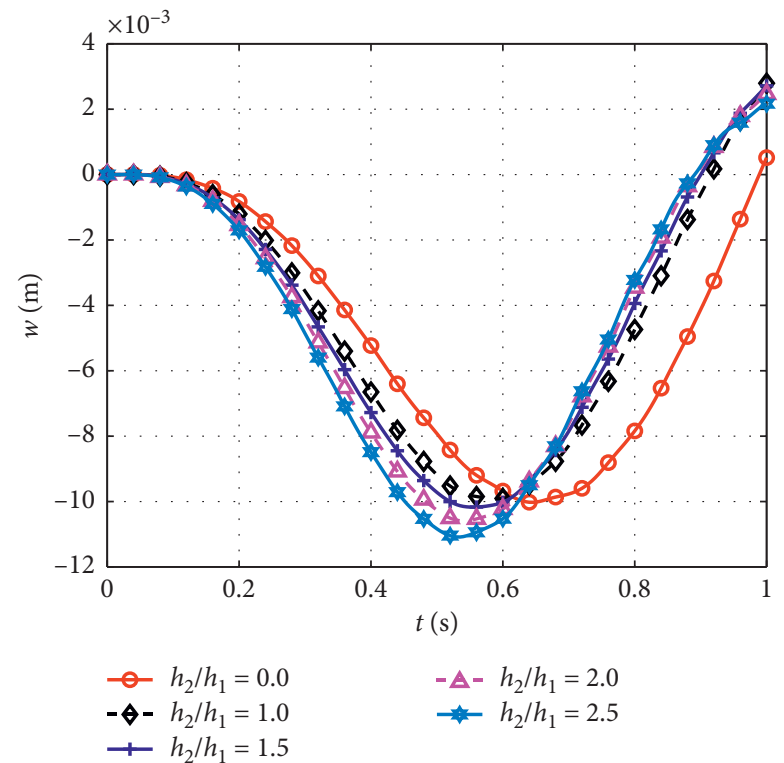

(a)

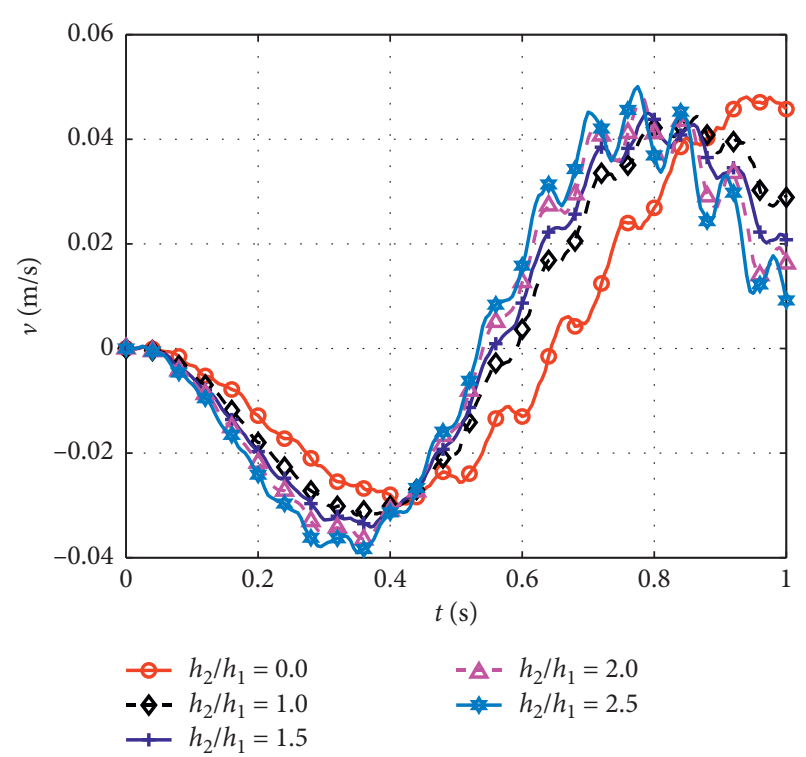

(b)

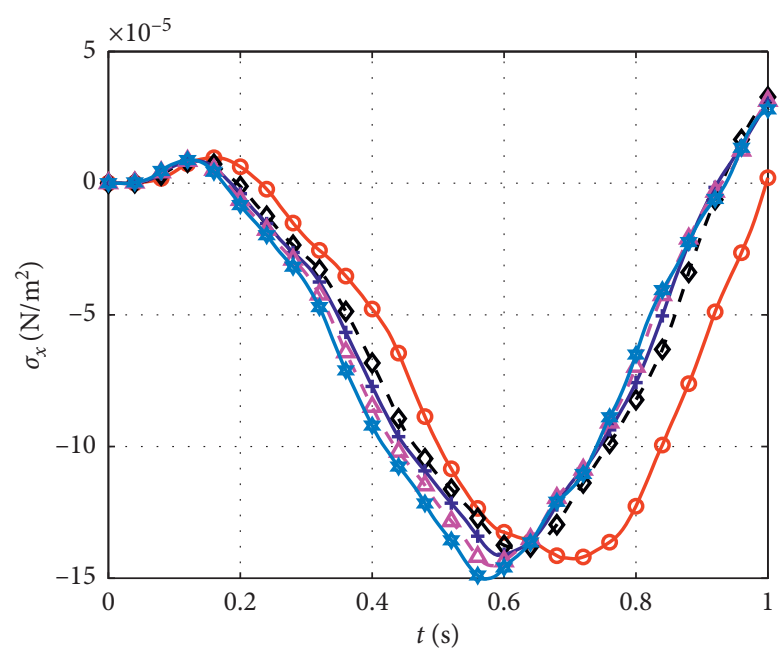

$$
\begin{array}{ll}
-h_{2} / h_{1}=0.0 & -\Delta-h_{2} / h_{1}=2.0 \\
-\diamond-h_{2} / h_{1}=1.0 & \quad-h_{2} / h_{1}=2.5 \\
-\boldsymbol{~} h_{2} / h_{1}=1.5 &
\end{array}
$$

(c)

\begin{tabular}{|c|c|c|c|c|c|}
\hline Maximum values & $h_{2} / h_{1}=0$ & $h_{2} / h_{1}=1$ & $h_{2} / h_{1}=1.5$ & $h_{2} / h_{1}=2$ & $h_{2} / h_{1}=2.5$ \\
\hline$w(\mathrm{~m})$ & 0.0100 & 0.0099 & 0.0102 & 0.0106 & 0.0111 \\
\hline$v\left(\mathrm{~m} / \mathrm{s}^{2}\right)$ & 0.0300 & 0.0319 & 0.0341 & 0.0365 & 0.0390 \\
\hline$\sigma_{x}(\mathrm{MPa})$ & 1.4262 & 1.3850 & 1.4129 & 1.4524 & 1.5024 \\
\hline Reduced mass (\%) & 0 & 27 & 34 & 40 & 45 \\
\hline
\end{tabular}

Figure 7: Dynamic deflections of the centre point of the plate versus time for different $h_{2} / h_{1}$ ratios. (a) Deflection $w$ versus time, (b) velocity $v$ versus time, and (c) stress $\sigma_{x}$ versus time.

TABLe 5: Maximum deflections, velocities, and stress of the plate central point. 


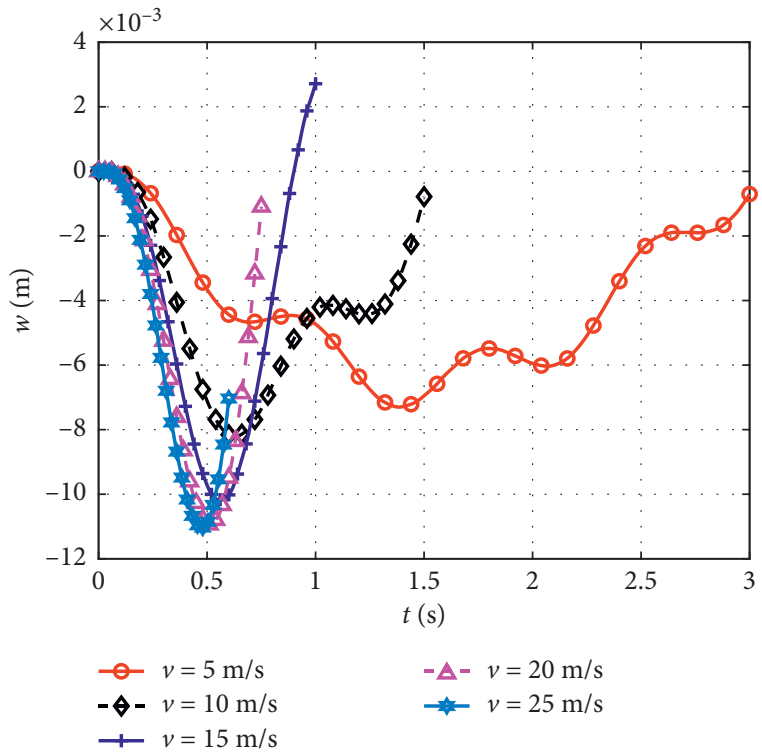

(a)

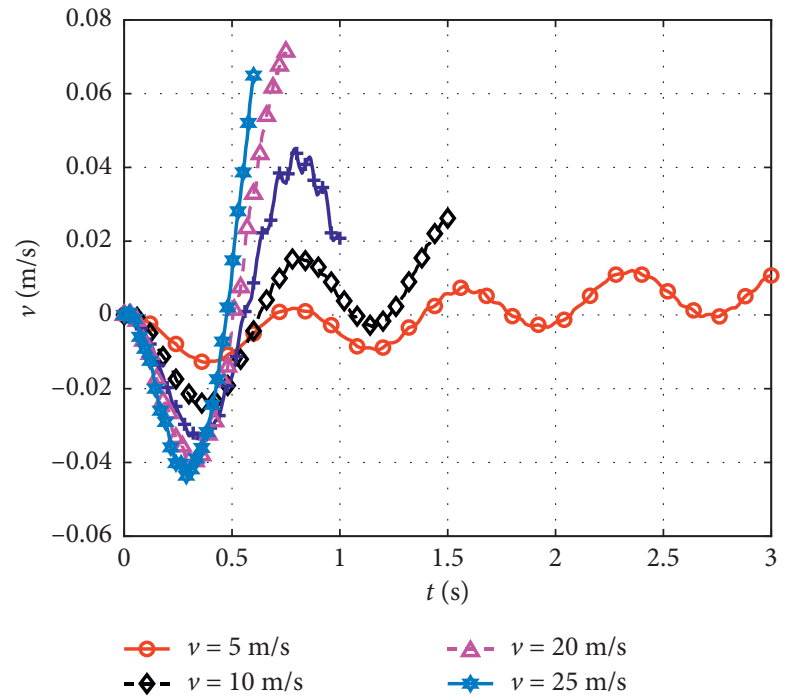

(b)

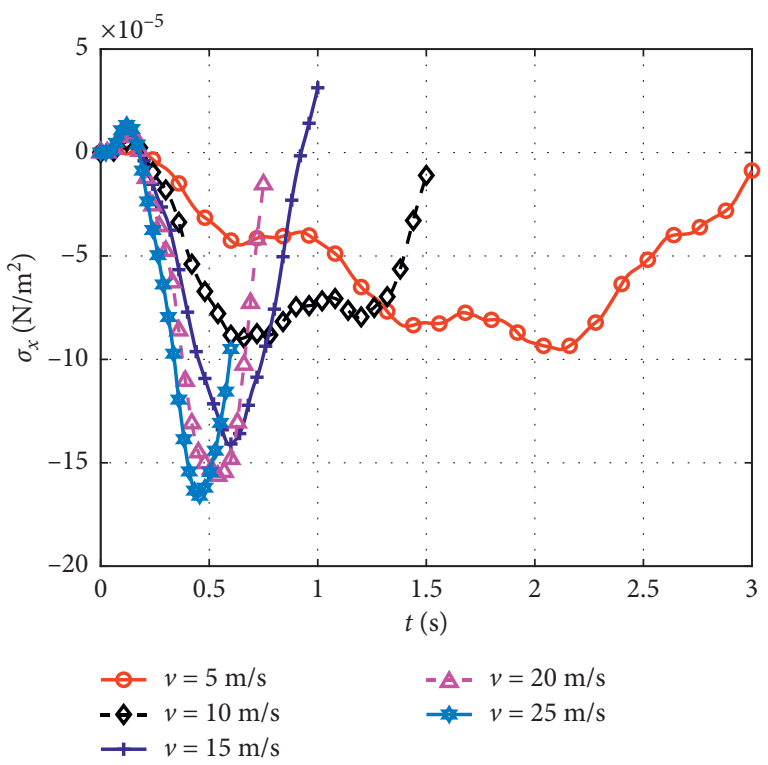

(c)

FIGURE 8: Dynamic deflections of the central point of the plate versus time for different velocities $v(\mathrm{~m} / \mathrm{s})$. (a) Deflection $w$ versus time, (b) velocity $v$ versus time, and (c) stress $\sigma_{x}$ versus time.

TABLe 6: Maximum deflections, velocities, and stress of the plate central point.

\begin{tabular}{|c|c|c|c|c|c|}
\hline Maximum values & $v=5 \mathrm{~m} / \mathrm{s}$ & $v=10 \mathrm{~m} / \mathrm{s}$ & $v=15 \mathrm{~m} / \mathrm{s}$ & $v=20 \mathrm{~m} / \mathrm{s}$ & $v=25 \mathrm{~m} / \mathrm{s}$ \\
\hline$w(\mathrm{~m})$ & 0.0073 & 0.0082 & 0.0102 & 0.0109 & 0.0110 \\
\hline$v\left(\mathrm{~m} / \mathrm{s}^{2}\right)$ & 0.0129 & 0.0245 & 0.0341 & 0.0407 & 0.0438 \\
\hline$\sigma_{x}(\mathrm{MPa})$ & 0.9525 & 0.9027 & 1.4129 & 1.5631 & 1.6626 \\
\hline
\end{tabular}

plate has very little change. Once again, it can be seen that the advantage of honeycomb sandwich composite plates is that it has a very good absorption capacity.
5.3.3. Influence of the Acceleration a. Next, let us consider a SFSF rectangular plate with $h=0.1 \mathrm{~m}, a=150 h, h / l=2$, $t / l=0.1385, K_{1}=K_{2}=0$, and $h_{2} / h_{1}=1.5$. The moving 


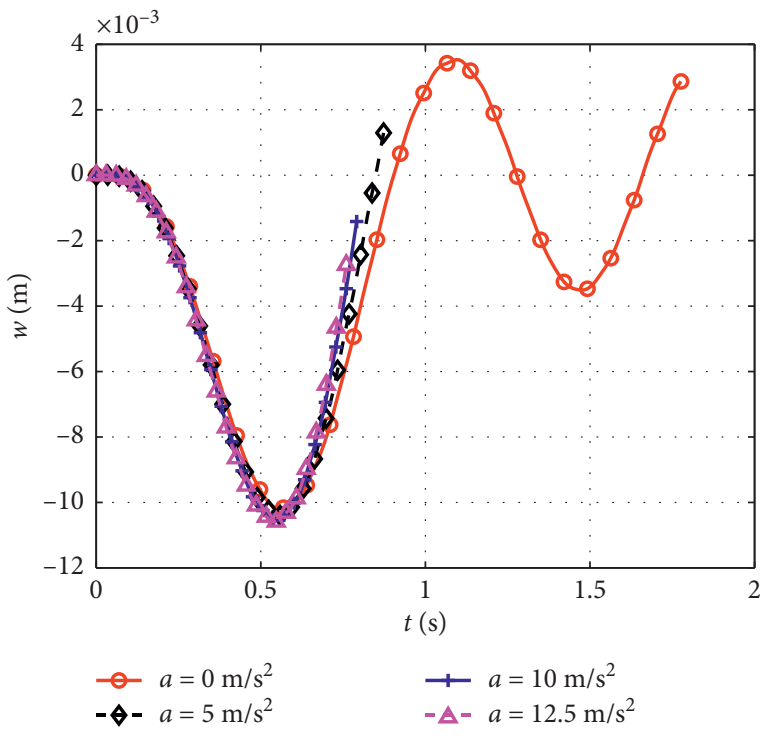

(a)

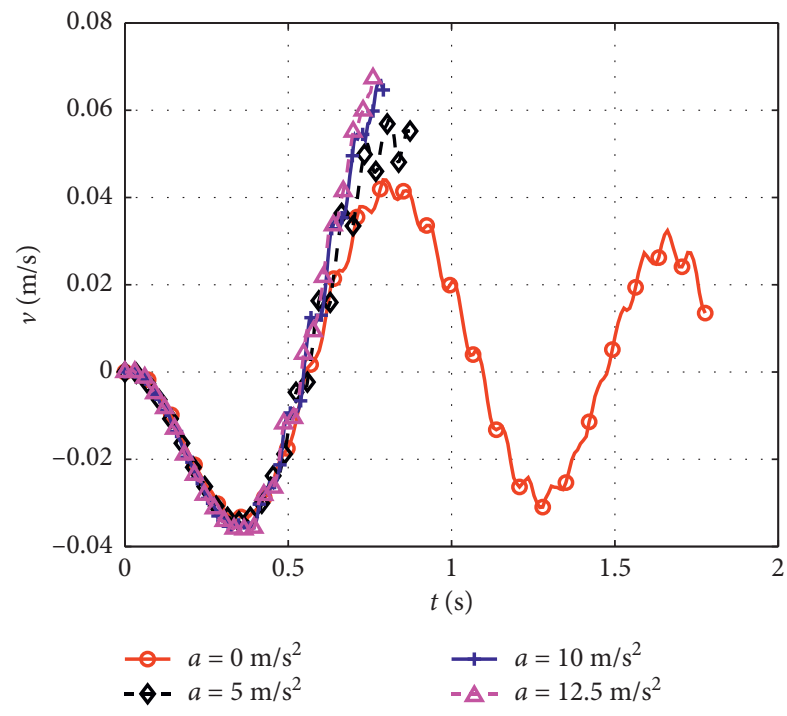

(b)

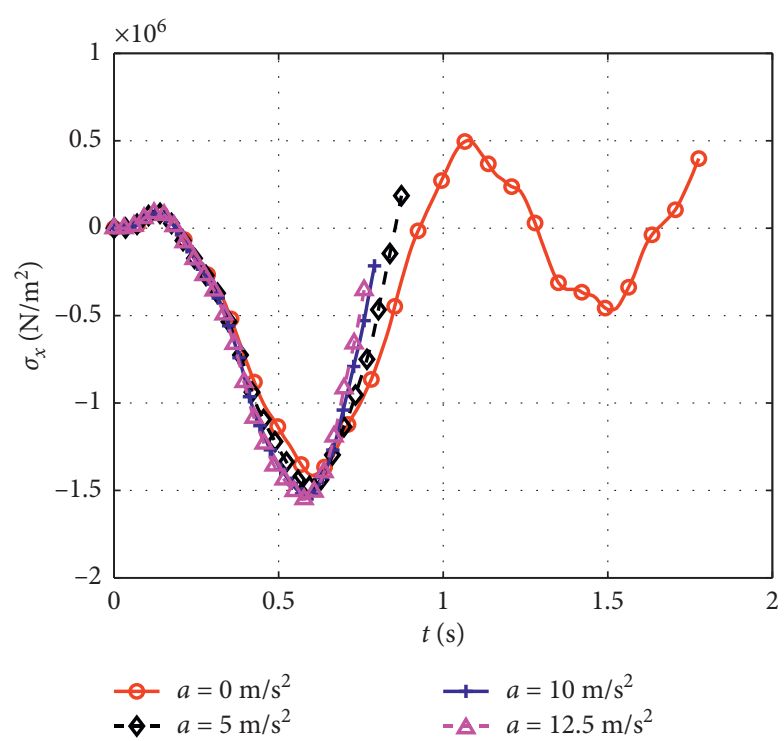

(c)

Figure 9: Dynamic deflections of the central point of the plate versus time for different acceleration $a\left(\mathrm{~m} / \mathrm{s}^{2}\right)$. (a) Deflection $w$ versus time, (b) velocity $v$ versus time, and (c) stress $\sigma_{x}$ versus time.

TABLE 7: Maximum deflections, velocities, and stress of the plate central point.

\begin{tabular}{lcccc}
\hline $\begin{array}{l}\text { Maximum } \\
\text { values }\end{array}$ & $a=0 \mathrm{~m} / \mathrm{s}^{2}$ & $a=5 \mathrm{~m} / \mathrm{s}^{2}$ & $a=10 \mathrm{~m} / \mathrm{s}^{2}$ & $a=12.5 \mathrm{~m} / \mathrm{s}^{2}$ \\
\hline$w(\mathrm{~m})$ & 0.0102 & 0.0104 & 0.0106 & 0.0106 \\
$v\left(\mathrm{~m} / \mathrm{s}^{2}\right)$ & 0.0334 & 0.0350 & 0.0365 & 0.0369 \\
$\sigma_{x}(\mathrm{MPa})$ & 1.4152 & 1.4766 & 1.5314 & 1.5499 \\
\hline
\end{tabular}

oscillator load with $m_{1}=m_{2}=100 \mathrm{~kg}, k=1.6 \mathrm{MN} / \mathrm{m}$, and $c=2500 \mathrm{Ns} / \mathrm{m}$ travels along $y=b / 2$ with velocity $v_{0}=15 \mathrm{~m} / \mathrm{s}$ and various accelerations $a=0,5,10$, and $12.5 \mathrm{~m} / \mathrm{s}^{2}$. The deflection, velocity, and stress of the plate central point are shown in Figure 9, and maximum deflections, velocities, and stress are illustrated in Table 7.
From Figure 9 and Table 7, it can be observed that when the acceleration of the moving load is increased from 0 to $12.5 \mathrm{~m} / \mathrm{s}^{2}$, deflection and velocity of the plate central point slightly increase. This proves that the acceleration of the moving load does not affect much the dynamic response of the sandwich composite plate with a honeycomb core layer.

5.3.4. Influence of $K_{1}$. Now, we consider a SFSF rectangular plate with $h=0.1 \mathrm{~m}, a=150 h, h / l=2, t / l=0.1385$, and $h_{2} /$ $h_{1}=1.5$, Winkler foundation stiffness $K_{1}=0,0.1,0.2,0.3$, $0.4 \mathrm{MPa} / \mathrm{m}$, and $K_{2}=0$. The moving oscillator load with $m_{1}=m_{2}=100 \mathrm{~kg}, k=1.6 \mathrm{MN} / \mathrm{m}$, and $c=2500 \mathrm{Ns} / \mathrm{m}$ moves along $y=b / 2$ with velocity $v=15 \mathrm{~m} / \mathrm{s}$ and acceleration $a=0$. The deflection, velocity, and stress of the plate central point 


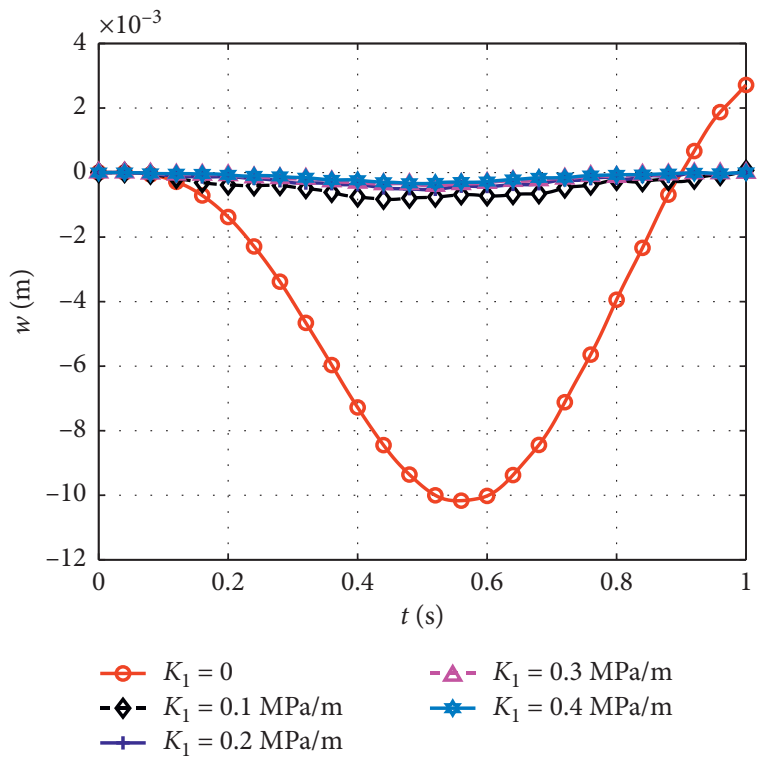

(a)

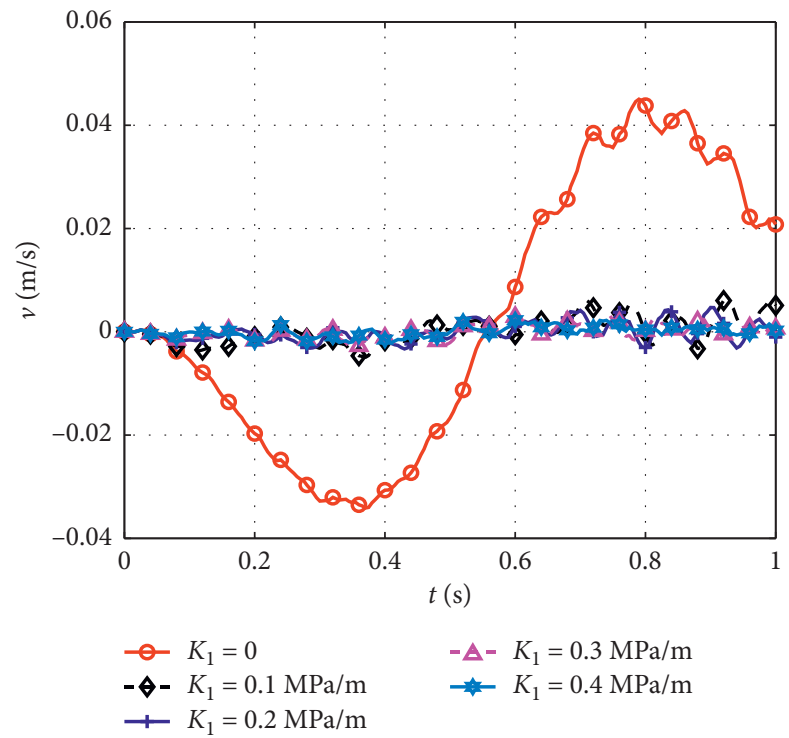

(b)

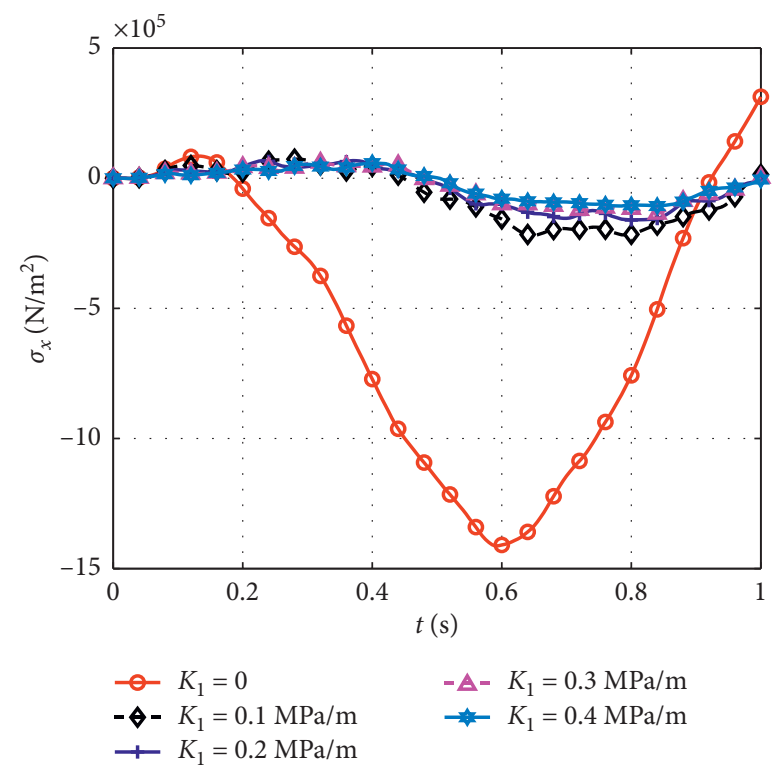

(c)

Figure 10: Deflections of the central point of the plate versus time for different Winkler foundation stiffness $K_{1}(\mathrm{MPa} / \mathrm{m})$. (a) Deflection $w$ versus time, (b) velocity $v$ versus time, and (c) stress $\sigma_{x}$ versus time.

TABLe 8: Maximum deflections, velocities, and stress of the plate central point.

\begin{tabular}{lccccc}
\hline Maximum values & $K_{1}=0.0(\mathrm{MPa} / \mathrm{m})$ & $K_{1}=0.1(\mathrm{MPa} / \mathrm{m})$ & $K_{1}=0.2(\mathrm{MPa} / \mathrm{m})$ & $K_{1}=0.3(\mathrm{MPa} / \mathrm{m})$ & $K_{1}=0.4(\mathrm{MPa} / \mathrm{m})$ \\
\hline$w(\mathrm{~m})$ & 0.0102 & 0.0008 & 0.0005 & 0.0004 & 0.0003 \\
$v(\mathrm{~m} / \mathrm{s})$ & 0.0341 & 0.0050 & 0.0033 & 0.0033 & 0.0021 \\
$\sigma_{x}(\mathrm{MPa})$ & 1.4129 & 0.2197 & 0.1605 & 0.1375 & 0.1067 \\
\hline
\end{tabular}

are shown in Figure 10, and maximum deflections, velocities, and stress are illustrated in Table 8.

Figure 10 and Table 8 show the effects of Winkler foundation stiffness on the dynamic response of the sandwich plates with negative Poisson's ratio. From these results, it can be seen that the EF makes the vibration amplitude of sandwich composite plates with negative Poisson's ratio reduce strongly. Furthermore, note that the EF according to Winkler's model significantly influences the dynamic response of the sandwich composite plate. 


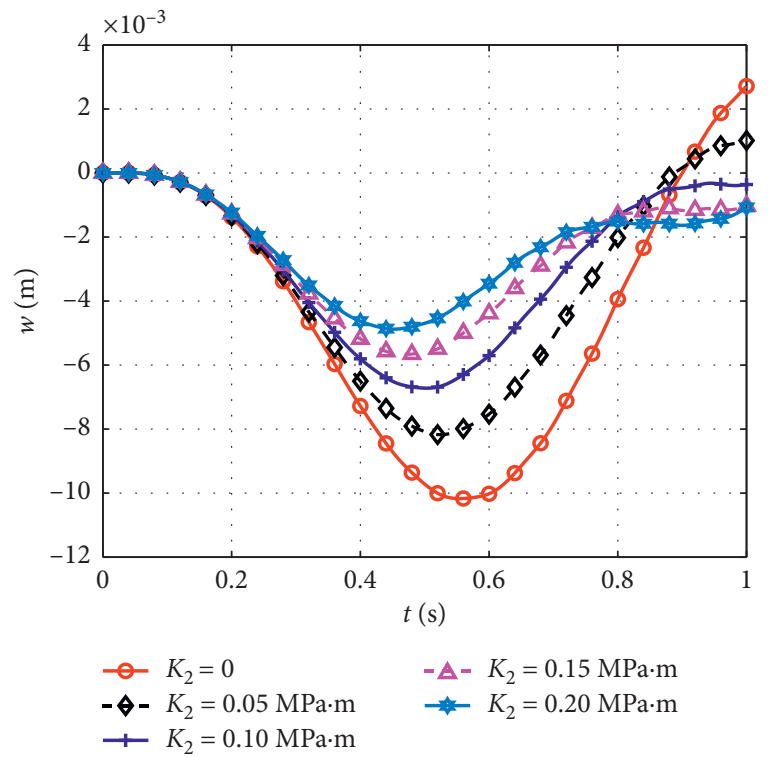

(a)

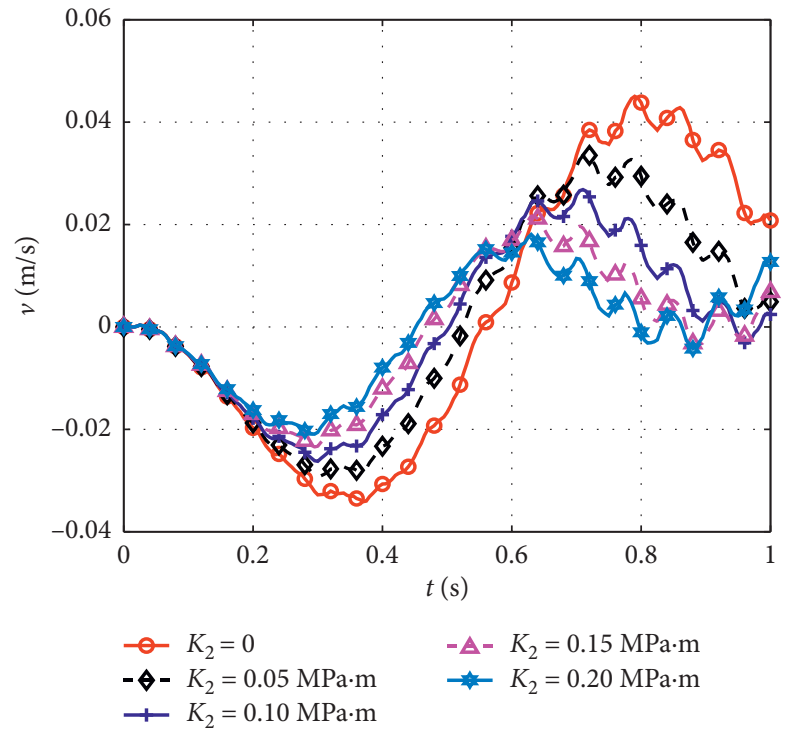

(b)

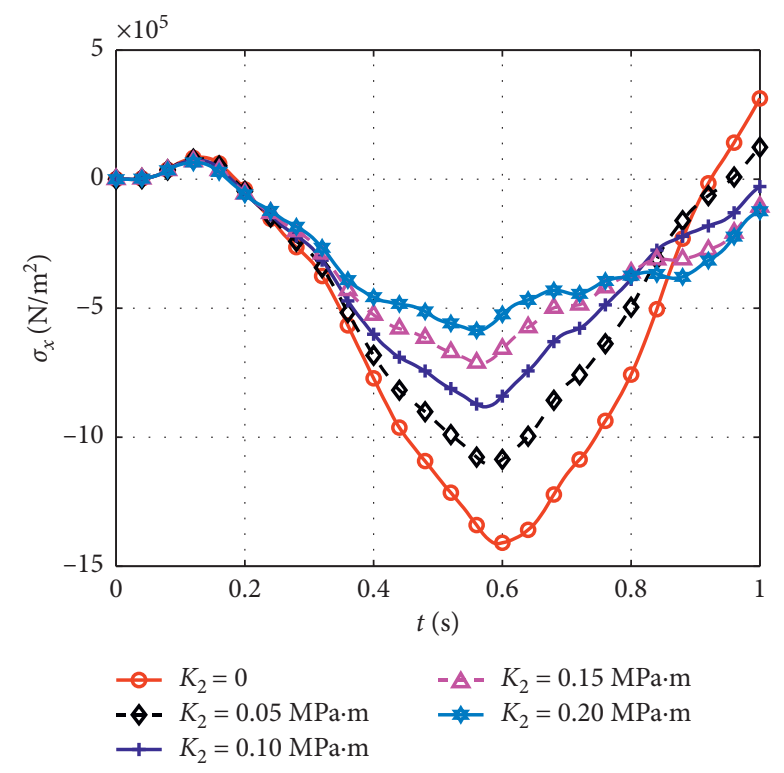

(c)

FIgURE 11: Effect of the Pasternak foundation $K_{2}(\mathrm{Mpa} \cdot \mathrm{m})$ on the dynamic response of the sandwich plates with negative Poisson's ratio. (a) Deflection $w$ versus time, (b) velocity $v$ versus time, and (c) stress $\sigma_{x}$ versus time.

TABLE 9: Maximum deflections, velocities, and stress of the plate central point.

\begin{tabular}{lccccc}
\hline Maximum values & $K_{2}=0.0(\mathrm{MPa} \cdot \mathrm{m})$ & $K_{2}=0.05(\mathrm{MPa} \cdot \mathrm{m})$ & $K_{2}=0.1(\mathrm{MPa} \cdot \mathrm{m})$ & $K_{2}=0.15(\mathrm{MPa} \cdot \mathrm{m})$ & $K_{2}=0.2(\mathrm{MPa} \cdot \mathrm{m})$ \\
\hline$w(\mathrm{~m})$ & 0.0102 & 0.0082 & 0.0067 & 0.0057 & 0.0049 \\
$v\left(\mathrm{~m} / \mathrm{s}^{2}\right)$ & 0.0341 & 0.0294 & 0.0262 & 0.0234 & 0.0209 \\
$\sigma_{x}(\mathrm{MPa})$ & 1.4129 & 1.1070 & 0.8821 & 0.7139 & 0.5857 \\
\hline
\end{tabular}

5.3.5. Influence of $K_{2}$. Finally, we investigate a SFSF rectangular plate with $h=0.1 \mathrm{~m}, a=150 h, h / l=2, t / l=0.1385$, $K_{1}=0$, and shear layer stiffness of Pasternak foundation $K_{2}=0,0.05,0.10,0.15,0.20 \mathrm{MPa} \cdot \mathrm{m}$. The moving oscillator load with $m_{1}=m_{2}=100 \mathrm{~kg}, k=1.6 \mathrm{~N} / \mathrm{m}$, and $c=2500 \mathrm{Ns} / \mathrm{m}$ moves along $y=b / 2$ with velocity $v=15 \mathrm{~m} / \mathrm{s}$ and acceleration $a=0$. The ratio $h_{2} / h_{1}=1.5$. The deflection, velocity, and stress of the plate central point are shown in Figure 11, and maximum deflections, velocities, and stress are shown in Table 9.

Figure 11 and Table 9 show the effects of the Pasternak foundation on the dynamic response of the sandwich 
composite plates with the honeycomb core layer. When $K_{2}$ increases, the response of deflections, velocities, and stress of the plate central point reduces and also it has a significant effect on the dynamic response of structures.

\section{Conclusion}

In the paper, the dynamic response of the sandwich composite plates with negative Poisson's ratio under moving oscillator load on EF is mainly studied. Reddy's first-order shear deformation plate theory is used to form the basic equations. By using FEM, the equation system of motion of the sandwich composite plates subjected to moving load is solved. From the numerical results, we can withdraw some of the following points:

(i) Authors built a numerical method to analyze the dynamical response of sandwich composite plates with honeycomb core layer under moving oscillator load on EF.

(ii) This investigation further clarifies the superiority of sandwich composite plates with negative Poisson's ratio in auxetic honeycomb core layer under moving oscillator load. It can be noted that using sandwich auxetic honeycomb plates significantly reduces the mass and increases the vibration absorbability of the structures.

(iii) This study also analyzes and discusses the effects of material and geometrical properties and EF on the dynamic response of sandwich composite plates with negative Poisson's ratio in auxetic honeycomb core layer.

(iv) The proposed method can analyze the static bending, dynamic response, and nonlinear problems of structures with the different honeycomb core layers, which can be not easily solved by analytical methods.

\section{Appendix}

\section{A. Shapes Function in Equation (16)}

Shape function in equation (16) is given by

$$
\begin{aligned}
& N_{1}=0.25(1-\xi)(1-\eta)(-\xi-\eta-1), \\
& N_{2}=0.5\left(1-\xi^{2}\right)(1-\eta) \\
& N_{3}=0.25(1+\xi)(1-\eta)(\xi-\eta-1), \\
& N_{4}=0.5(1+\xi)\left(1-\eta^{2}\right) \\
& N_{5}=0.25(1+\xi)(1+\eta)(\xi+\eta-1), \\
& N_{6}=0.5\left(1-\xi^{2}\right)(1+\eta) \\
& N_{7}=0.25(1-\xi)(1+\eta)(-\xi+\eta-1), \\
& N_{8}=0.5(1-\xi)\left(1-\eta^{2}\right)
\end{aligned}
$$

where $\xi$ and $\eta$ are natural coordinates.

\section{B. The Matrices in Equation (20)}

The matrices in equation (20) are given by

$$
\begin{aligned}
& B_{1}^{i}=\left[\begin{array}{ccccc}
\frac{\partial N_{i}}{\partial x} & 0 & 0 & 0 & 0 \\
0 & \frac{\partial N_{i}}{\partial y} & 0 & 0 & 0 \\
\frac{\partial N_{i}}{\partial y} & \frac{\partial N_{i}}{\partial x} & 0 & 0 & 0
\end{array}\right], \\
& B_{2}^{i}=\left[\begin{array}{ccccc}
0 & 0 & 0 & \frac{\partial N_{i}}{\partial x} & 0 \\
0 & 0 & 0 & 0 & \frac{\partial N_{i}}{\partial y} \\
0 & 0 & 0 & \frac{\partial N_{i}}{\partial y} & \frac{\partial N_{i}}{\partial x}
\end{array}\right], \\
& B_{3}^{i}=\left[\begin{array}{ccccc}
0 & 0 & \frac{\partial N_{i}}{\partial y} & 0 & N_{i} \\
0 & 0 & \frac{\partial N_{i}}{\partial x} & N_{i} & 0
\end{array}\right],
\end{aligned}
$$

with $i=1, \ldots, 8$ (number nodes per element).

\section{The Matric in Equation (23)}

The matrix in equation (23) is shown as follows:

$N_{w}=\left[0_{1 \times 2}, N_{1}, 0_{1 \times 4}, N_{2}, 0_{1 \times 4}, N_{3}, \ldots 0_{1 \times 4}, N_{7}, 0_{1 \times 4}, N_{8}, 0_{1 \times 2}\right]$.

\section{Data Availability}

The data used to support the findings of this study are included within the article.

\section{Conflicts of Interest}

The authors declare that they have no conflicts of interest.

\section{Acknowledgments}

This research was funded by Vietnam National Foundation for Science and Technology Development (NAFOSTED) under Grant no. 107.02-2019.330.

\section{References}

[1] R. F. Almgren, "An isotropic three-dimensional structure with Poisson's ratio $=-1$," Journal of Elasticity, vol. 15, no. 4, pp. 427-430, 1985.

[2] J. P. M. Whitty, A. Alderson, P. Myler, and B. Kandola, "Towards the design of sandwich panel composites with 
enhanced mechanical and thermal properties by variation of the in-plane Poisson's ratios," Composites Part A: Applied Science and Manufacturing, vol. 34, no. 6, pp. 525-534, 2003.

[3] M. Ruzzene, L. Mazzarella, P. Tsopelas, and F. Scarpa, "Wave propagation in sandwich plates with periodic auxetic core," Journal of Intelligent Material Systems and Structures, vol. 13, no. 9, pp. 587-597, 2002.

[4] A. Jensen, H. Zhao, A. Norbury et al., "Effects of Poisson's ratio on the deformation of thin membrane structures under indentation," Phys Status Solidi B, vol. 252, no. 7, pp. 15261532, 2015.

[5] D. Qing-Tian and Y. Zhi-Chun, "Wave propagation in sandwich panel with auxetic core," Journal of Solid Mechanics, vol. 2, pp. 393-402, 2010.

[6] E. P. Hadjigeorgiou and G. E. Stavroulakis, "The use of auxetic materials in smart structures," Computational Methods in Science and Technology, vol. 10, no. 2, pp. 147-160, 2004.

[7] L. Teik-Cheng, "Shear deformation in thick auxetic plates," Smart Materials and Structures, vol. 22, no. 8, Article ID 084001, 2013.

[8] L. Teik-Cheng, "Auxetic plates on auxetic foundation," Advanced Materials Research, vol. 974, pp. 398-401, 2014.

[9] L. Teik-Cheng, "Thermal stresses in auxetic plates and shells," Mechanics of Advanced Materials and Structures, vol. 22, no. 3, pp. 205-212, 2015.

[10] Y. Prawoto, "Seeing auxetic materials from the mechanics point of view: a structural review on the negative Poisson's ratio," Computational Materials Science, vol. 58, pp. 140-153, 2012.

[11] T. Strek, H. Jopek, and M. Nienartowicz, "Dynamic response of sandwich panels with auxetic cores," Physica Status Solidi (B), vol. 252, no. 7, pp. 1540-1550, 2015.

[12] F. Scarpa and G. Tomlinson, "Theoretical characteristics of the vibration of sandwich plates with in-plane negative Poisson's ratio values," Journal of Sound and Vibration, vol. 230, no. 1, pp. 45-67, 2000.

[13] D. U. Yang, S. Lee, and F. Y. Huang, "Geometric effects on micropolar elastic honeycomb structure with negative Poisson's ratio using the finite element method," Finite Elements in Analysis and Design, vol. 39, no. 3, pp. 187-205, 2003.

[14] G. Imbalzano, P. Tran, T. D. Ngo, and P. V. Lee, "Threedimensional modelling of auxetic sandwich panels for localised impact resistance," Journal of Sandwich Structures \& Materials, vol. 19, no. 3, pp. 291-316, 2015.

[15] G. Imbalzano, P. Tran, T. D. Ngo, and P. V. S. Lee, "A numerical study of auxetic composite panels under blast loadings," Composite Structures, vol. 135, pp. 339-352, 2016.

[16] J. Huang, X. Gong, Q. Zhang, F. Scarpa, Y. Liu, and J. Leng, "In-plane mechanics of a novel zero Poisson's ratio honeycomb core," Composites Part B: Engineering, vol. 89, pp. 6776, 2016.

[17] T. Jin, Z. W. Zhou, Z. G. Liu et al., "Size effects on the in-plane mechanical behavior of hexagonal honeycombs," Science and Engineering of Composite Materials, vol. 23, pp. 301-307, 2016.

[18] J. Arbaoui, Y. Schmitt, P. J-Luc et al., "Numerical simulation and experimental bending behaviour of multi-layer sandwich structures," Journal of Theoretical and Applied Mechanics, vol. 52, no. 2, pp. 431-442, 2014.

[19] Z. Yongcun, L. Xiaobin, and L. Shutian, "Enhancing buckling capacity of a rectangular plate under uniaxial compression by utilizing an auxetic material," Chinese Journal of Aeronautics, vol. 29, no. 4, pp. 945-951, 2016.
[20] X. Xu and Z. Deng, "Wave propagation characteristics in thick conventional and auxetic cellular plates," Acta Mechanica Solida Sinica, vol. 29, no. 2, pp. 159-166, 2016.

[21] D. D. Nguyen and C. H. Pham, "Nonlinear dynamic response and vibration of sandwich composite plates with negative Poisson's ratio in auxetic honeycombs," Journal of Sandwich Structures \& Materials, vol. 20, no. 6, pp. 692-717, 2018.

[22] P. H. Cong, P. M. Phuc, H. T. Thiem, D. T. Manh, and N. D. Duc, "Static bending analysis of auxetic plate by FEM and a new third-order shear deformation plate theory," $V N U$ Journal of Science: Natural Sciences and Technology, vol. 36, no. 1, pp. 90-99, 2020.

[23] N. D. Duc, K. Seung-Eock, N. D. Tuan, P. Tran, and N. D. Khoa, "New approach to study nonlinear dynamic response and vibration of sandwich composite cylindrical panels with auxetic honeycomb core layer," Aerospace Science and Technology, vol. 70, pp. 396-404, 2017.

[24] P. H. Cong, P. T. Long, N. Van Nhat, and N. D. Duc, "Geometrically nonlinear dynamic response of eccentrically stiffened circular cylindrical shells with negative Poisson's ratio in auxetic honeycombs core layer," International Journal of Mechanical Sciences, vol. 152, pp. 443-453, 2019.

[25] P. H. Cong, N. D. Khanh, N. D. Khoa, and N. D. Duc, "New approach to investigate nonlinear dynamic response of sandwich auxetic double curves shallow shells using TSDT," Composite Structures, vol. 185, pp. 455-465, 2018.

[26] T.-D. Nguyen and N. D. Duc, "Evaluation of elastic properties and thermal expansion coefficient of composites reinforced by randomly distributed spherical particles with negative Poisson's ratio," Composite Structures, vol. 153, pp. 569-577, 2016.

[27] A. Zenkour and A. Radwan, "Free vibration analysis of multilayered composite and soft core sandwich plates resting on Winkler-Pasternak foundations," Journal of Sandwich Structures \& Materials, vol. 20, no. 2, pp. 169-190, 2018.

[28] N. D. Duc, D. H. Bich, and P. H. Cong, "Nonlinear thermal dynamic response of shear deformable FGM plates on elastic foundations," Journal of Thermal Stresses, vol. 39, no. 3, pp. 278-297, 2016.

[29] N. D. Duc, K. Seung-Eock, P. H. Cong, N. T. Anh, and N. D. Khoa, "Dynamic response and vibration of composite double curved shallow shells with negative Poisson's ratio in auxetic honeycombs core layer on elastic foundations subjected to blast and damping loads," International Journal of Mechanical Sciences, vol. 133, pp. 504-512, 2017.

[30] N. D. Duc, Nonlinear Static and Dynamic Stability of Functionally Graded Plates and Shells, Vietnam National University Press, Hanoi, Vietnam, 2014.

[31] A. Mahmoudi, S. Benyoucef, A. Tounsi, A. Benachour, E. A. Adda Bedia, and S. Mahmoud, "A refined quasi-3D shear deformation theory for thermo-mechanical behavior of functionally graded sandwich plates on elastic foundations," Journal of Sandwich Structures \& Materials, vol. 21, no. 6, pp. 1906-1929, 2019.

[32] Q. Song, J. Shi, and Z. Liu, "Vibration analysis of functionally graded plate with a moving mass," Applied Mathematical Modelling, vol. 46, pp. 141-160, 2017.

[33] P. Malekzadeh, A. R. Fiouz, and H. Razi, “Three-dimensional dynamic analysis of laminated composite plates subjected to moving load," Composite Structures, vol. 90, no. 2, pp. 105$114,2009$.

[34] H. Ouyang, "Moving-load dynamic problems: a tutorial (with a brief overview)," Mechanical Systems and Signal Processing, vol. 25, no. 6, pp. 2039-2060, 2011. 
[35] H.-N. Nguyen, T.-Y. Nguyen, K. Tran et al., "A finite element model for dynamic analysis of triple-layer composite plates with layers connected by shear connectors subjected to moving load," Materials, vol. 12, no. 4, p. 598, 2019.

[36] Q. Song, J. Shi, Z. Liu, and Y. Wan, "Dynamic analysis of rectangular thin plates of arbitrary boundary conditions under moving loads," International Journal of Mechanical Sciences, vol. 117, pp. 16-29, 2016.

[37] L. Fryba, Vibration of Solids and Structures under Moving Loads, Institute of Theorical and Applied Mechannics, Academy of Sciences of the Czech Republic, Prague, Czechia, 1999.

[38] J. N. Reddy, Mechanics of Laminated Composite Plates and Shells; Theory and Analysis, CRC Press, Boca Raton, FL, USA, 2004.

[39] Nguyen, Canh, Thanh, Ke, Phan, and Thom, "Finite element modelling of a composite shell with shear connectors," Symmetry, vol. 11, no. 4, p. 527, 2019.

[40] T. T. Tran, V. K. Tran, P. B. Le, V. M. Phung, V. T. Do, and H. N. Nguyen, "Forced vibration analysis of laminated composite shells reinforced with graphene nanoplatelets using finite element method," Advances in Civil Engineering, vol. 2020, Article ID 1471037, 17 pages, 2020.

[41] K. Reddy, J. S. Kumar, C. E. Reddy, and B. Reddy, "Free vibration behaviour of functionally graded plates using higher-oder shear deformation theory," Journal of Applied Science and Engineering, vol. 17, no. 3, pp. 231-241, 2014. 